\title{
Eddy covariance fluxes of acyl peroxy nitrates (PAN, PPN and MPAN) above a Ponderosa pine forest
}

\author{
G. M. Wolfe ${ }^{1}$, J. A. Thornton ${ }^{2}$, R. L. N. Yatavelli ${ }^{2}$, M. McKay ${ }^{3}$, A. H. Goldstein ${ }^{3}$, B. LaFranchi ${ }^{4}$, K.-E. Min ${ }^{4}$, and \\ R. C. Cohen ${ }^{4}$ \\ ${ }^{1}$ Department of Chemistry, University of Washington, Seattle, WA, USA \\ ${ }^{2}$ Department of Atmospheric Sciences, University of Washington, Seattle, WA, USA \\ ${ }^{3}$ Department of Environmental Science, Policy, and Management, University of California, Berkeley, CA, USA \\ ${ }^{4}$ Department of Chemistry, University of California, Berkeley, CA, USA
}

Received: 20 August 2008 - Published in Atmos. Chem. Phys. Discuss.: 25 September 2008

Revised: 5 December 2008 - Accepted: 11 December 2008 - Published: 27 January 2009

\begin{abstract}
During the Biosphere Effects on AeRosols and Photochemistry EXperiment 2007 (BEARPEX-2007), we observed eddy covariance (EC) fluxes of speciated acyl peroxy nitrates (APNs), including peroxyacetyl nitrate (PAN), peroxypropionyl nitrate (PPN) and peroxymethacryloyl nitrate (MPAN), above a Ponderosa pine forest in the western Sierra Nevada. All APN fluxes are net downward during the day, with a median midday PAN exchange velocity of $-0.3 \mathrm{~cm} \mathrm{~s}^{-1}$; nighttime storage-corrected APN EC fluxes are smaller than daytime fluxes but still downward. Analysis with a standard resistance model shows that loss of PAN to the canopy is not controlled by turbulent or molecular diffusion. Stomatal uptake can account for 25 to $50 \%$ of the observed downward PAN flux. Vertical gradients in the PAN thermal decomposition (TD) rate explain a similar fraction of the flux, suggesting that a significant portion of the PAN flux into the forest results from chemical processes in the canopy. The remaining "unidentified" portion of the net PAN flux $(\sim 15 \%)$ is ascribed to deposition or reactive uptake on nonstomatal surfaces (e.g. leaf cuticles or soil). Shifts in temperature, moisture and ecosystem activity during the summer fall transition alter the relative contribution of stomatal uptake, non-stomatal uptake and thermochemical gradients to the net PAN flux. Daytime PAN and MPAN exchange velocities are a factor of 3 smaller than those of PPN during the first two weeks of the measurement period, consistent with strong intra-canopy chemical production of PAN and MPAN
\end{abstract}

Correspondence to: J. A. Thornton (thornton@atmos.washington.edu) during this period. Depositional loss of APNs can be 3-21\% of the gross gas-phase TD loss depending on temperature. As a source of nitrogen to the biosphere, PAN deposition represents approximately $4-19 \%$ of that due to dry deposition of nitric acid at this site.

\section{Introduction}

Surface uptake of reactive nitrogen provides a key pathway through which anthropogenic emissions may influence ecosystem vitality. Carbon sequestration within boreal forests may be largely controlled by wet and dry deposition of atmospheric nitrogen, the bulk of which derives from anthropogenic activities (Magnani et al., 2007). Excessive nitrification may give rise to soil acidification, reduced plant resistance to environmental stresses (e.g. drought and ozone) and increased nitrate concentrations in runoff (Bytnerowicz and Fenn, 1996; Goulding et al., 1998). As a primary sink for total atmospheric reactive nitrogen $\left(\mathrm{NO}_{\mathrm{y}} \equiv \mathrm{NO}+\mathrm{NO}_{2}+\mathrm{HNO}_{3}+\mathrm{HONO}+\right.$ peroxynitrates+alkyl nitrates $+2 \mathrm{~N}_{2} \mathrm{O}_{5}+\mathrm{ClNO}_{2}+\ldots$ ), nitrogen deposition also impacts the oxidative capacity of the troposphere. In the planetary boundary layer, $\mathrm{NO}_{\mathrm{x}}\left(\equiv \mathrm{NO}+\mathrm{NO}_{2}\right)$ radicals undergo rapid $(\sim 4 \mathrm{~h})$ conversion into temporary or permanent reservoir species, including peroxy nitrates, alkyl nitrates, and nitric acid (Roberts, 1990; Murphy et al., 2007). Loss of $\mathrm{NO}_{\mathrm{y}}$ is believed to occur primarily via wet and dry deposition of nitric acid $\left(\mathrm{HNO}_{3}\right)$, which is formed by gas-phase reaction of $\mathrm{OH}$ and $\mathrm{NO}_{2}$, as well as by reactions involving $\mathrm{N}_{2} \mathrm{O}_{5}$ and $\mathrm{NO}_{3}$. Dry deposition of $\mathrm{HNO}_{3}$ to vegetation is typically assumed to be limited by vertical mixing processes, giving rise

Published by Copernicus Publications on behalf of the European Geosciences Union. 
to a typical $\mathrm{HNO}_{3}$ lifetime of 5-10 h near the surface (Sievering et al., 2001; Brown et al., 2004; Pryor and Klemm, 2004; Day et al., 2008); thus, a few hours downwind of $\mathrm{NO}_{\mathrm{x}}$ source regions, the $\mathrm{NO}_{\mathrm{y}}$ budget can become dominated by longer-lived nitrogen oxide reservoirs, including acyl peroxy nitrates (APNs). Although the gas-phase sources and sinks of APNs are generally well understood, the role of depositional processes remains a point of controversy and is poorly constrained in current models (Wesely and Hicks, 2000).

APNs are formed during the photochemical oxidation of volatile organic compounds (VOC) in the presence of $\mathrm{NO}_{\mathrm{X}}$ :

$\mathrm{RC}(\mathrm{O}) \mathrm{O}_{2}+\mathrm{NO}_{2} \rightleftharpoons \mathrm{RC}(\mathrm{O}) \mathrm{O}_{2} \mathrm{NO}_{2} \quad$ (R1a, R1b)

This equilibrium exhibits a strong temperature dependence, with typical APN thermal decomposition lifetimes ranging from a few hours at $298 \mathrm{~K}$ to days or weeks at temperatures below $273 \mathrm{~K}$. Net APN lifetimes are ultimately controlled by the fate of the acyl peroxy radical $\left(\mathrm{RC}(\mathrm{O}) \mathrm{O}_{2}\right)$, which can reform an APN via reaction with $\mathrm{NO}_{2}$ or be lost via reaction with $\mathrm{NO}, \mathrm{RO}_{2}$ or $\mathrm{HO}_{2}$. APNs with unsaturated hydrocarbon chains are also labile towards oxidation by $\mathrm{OH}$ and $\mathrm{O}_{3}$. As temporary reservoirs for $\mathrm{NO}_{2}$, APNs can redistribute $\mathrm{NO}_{\mathrm{x}}$ on regional and global scales, allowing for $\mathrm{O}_{3}$ production far from source regions (Moxim et al., 1996; Kotchenruther et al., 2001; Hudman et al., 2004; Parrish et al., 2004). APNs constitute $10-80 \%$ of total $\mathrm{NO}_{\mathrm{y}}$ in urban plumes, depending on transport time, meteorological conditions and photochemical history (Roberts, 1990; Roberts et al., 2004; Cleary et al., 2007; Murphy et al., 2007; Day et al., 2008). Peroxyacetyl nitrate (PAN, $\mathrm{R}=\mathrm{CH}_{3}$ ) typically comprises $80-90 \%$ of the speciated APN budget and is generated by the oxidation of both biogenic and anthropogenic VOC in the presence of $\mathrm{NO}_{\mathrm{x}}$ (Roberts, 1990). Other APNs have more specific VOC precursors; for example, peroxypropionyl nitrate $\left(\mathrm{PPN}, \mathrm{R}=\mathrm{CH}_{3} \mathrm{CH}_{2}\right.$ ) is generally attributed to the oxidation of n-alkanes, while peroxymethacryloyl nitrate (MPAN, $\mathrm{R}=\mathrm{CH}_{2} \mathrm{C}\left(\mathrm{CH}_{3}\right)$ ) is formed from methacrolein, an isoprene oxidation product.

Despite the significance of APNs as $\mathrm{NO}_{\mathrm{x}}$ reservoirs and phytotoxic pollutants (Taylor, 1969), deposition of these compounds is still poorly understood. Early investigations of APN uptake to vegetation report deposition velocities of 0 to $1 \mathrm{~cm} \mathrm{~s}^{-1}$. These estimates derive from indirect fluxgradient or kinetic methods and are limited to relatively simple surfaces (e.g. grass or soil) or nighttime measurements (Hill, 1971; Garland and Penkett, 1976; Dollard et al., 1990; Shepson et al., 1992; Schrimpf et al., 1996; Doskey et al., 2004). Advances in instrumentation have since permitted the use of more direct measurement techniques, such as eddy covariance (EC); however, results are far from conclusive. A recent 12-day set of speciated APN EC flux measurements demonstrates downward fluxes over a Loblolly pine plantation (Turnipseed et al., 2006) with magnitudes similar to prior studies and consistent with leaf-level uptake experiments (Okano et al., 1990; Sparks et al., 2003). In contrast,
Farmer and Cohen (2008) report a noon summertime upward flux (efflux) velocity of $+0.7 \mathrm{~cm} \mathrm{~s}^{-1}$ for total peroxy nitrates over a Ponderosa pine forest, which they attribute to withincanopy photochemical production that occurs faster than depositional loss. Accurate modeling of atmosphere-ecosystem interactions and within-canopy chemistry requires a more complete understanding of canopy-level APN fluxes. The fate of nitrogen entering foliage via APN deposition remains unclear, but this channel may contribute as much as $20 \%$ to total $\mathrm{N}$ deposition in some regions (Sparks et al., 2003).

As part of the Biosphere Effects on AeRosols and Photochemistry EXperiment 2007 (BEARPEX-2007), we deployed our thermal dissociation - chemical ionization mass spectrometer to measure EC fluxes and vertical concentration gradients of a suite of APNs above and within a Ponderosa pine forest. Here, we report on EC fluxes of PAN, PPN and MPAN. To date, this work represents the single longest record of direct, speciated APN fluxes measured via the EC method. Observations indicate downward daytime fluxes with magnitudes similar to those found in previous studies, although our analysis suggests that factors other than dry deposition contribute significantly to net APN fluxes. We explore the connection between above-canopy APN fluxes and intra-canopy processes, including stomatal uptake, thermal decomposition and APN production. All of these contribute to the observed fluxes, though the magnitude of each varies with environmental conditions. We also estimate the importance of APN deposition as a sink for atmospheric $\mathrm{NO}_{\mathrm{y}}$ and a source of fixed nitrogen to the biosphere.

\section{Methods}

Below, we summarize the key details of our measurement techniques and data reduction procedures. An extended discussion of Sect. 2.2-2.3 may be found in Appendix A.

\subsection{Research site and campaign}

The BEARPEX-2007 research intensive was designed to examine atmospheric chemistry at the urban-rural interface, including the chemical evolution of urban plumes and forestatmosphere interactions. The campaign was a collaborative effort, with over ten institutions measuring a full range of chemical, particulate and meteorological parameters. Observations of APNs were made from $24 \mathrm{Au}-$ gust to 8 October 2007 (Julian day of year 236 to 281) within and above a Ponderosa pine plantation owned by Sierra Pacific Industries and adjacent to the University of California at Berkeley's Blodgett Forest Research Station (BFRS). BFRS is located in the western foothills of the Sierra Nevada mountains $\left(38^{\circ} 58^{\prime} 42.9^{\prime \prime} \mathrm{N}, 120^{\circ} 57^{\prime} 57.9^{\prime \prime} \mathrm{W}\right.$, $1315 \mathrm{~m}$ ), $\sim 75 \mathrm{~km}$ northeast of Sacramento, and has been described in detail elsewhere (Goldstein et al., 2000). The site experiences a Mediterranean climate typified by hot, dry summers and cool, wet winters, with the transition from dry 
to wet occurring throughout September. Summertime winds are consistently westerly to southwesterly during the day and northeasterly to easterly at night, leading to regular diurnal cycles in trace gas mixing ratios characterized by the arrival of the Sacramento urban plume during the late afternoon followed by downslope advection of cleaner mountain air throughout the night (Dillon et al., 2002; Murphy et al., 2007). The canopy is composed mainly of Pinus ponderosa L. planted in 1990, with a few Douglas fir, white fir and incense cedar dispersed throughout. The understory is primarily mountain whitethorn (Ceanothus cordulatus) and manzanita (Arcostaphylos spp.) shrubs with heights up to $2 \mathrm{~m}$. Mean tree height within the daytime fetch was $h_{c}=7.9 \mathrm{~m}$ (displacement height $d=0.75 h_{c}=5.9 \mathrm{~m}$ ). One-sided leaf area index (LAI) for the full canopy (overstory and understory) is estimated at $5.1 \mathrm{~m}^{2} \mathrm{~m}^{-2}$ based on a tree survey conducted in early October 2007 and previous surveys of tree and brush leaf area (Xu et al., 2001; Misson et al., 2005).

The site included two sampling towers: the original $15 \mathrm{~m}$ walk-up tower, and a new $18 \mathrm{~m}$ scaffolding tower located $\sim 10 \mathrm{~m}$ north of the old tower. Inlets for APN measurements were located on the north tower. In our analysis, we employ measurements of ozone mixing ratios and fluxes (Bauer et al., 2000), vertical temperature gradients, water vapor flux and canopy needle temperature made on or near the south tower. Technical aspects of the meteorological measurements are described elsewhere (Goldstein et al., 2000). Other observations used in our analysis include laser-induced fluorescence measurements of $\mathrm{NO}_{2}$ and $\mathrm{HO}_{2}$ (Faloona et al., 2004) taken on or adjacent to the north tower. Power was provided by a propane generator situated $125 \mathrm{~m}$ north of the new tower, perpendicular to our sampling location and the prevailing daytime wind direction. As in previous campaigns at this site, generator exhaust plumes were often detected by other instrumentation (e.g. carbon monoxide monitors) during nighttime when winds were low and variable, but not during the daytime. Visual inspection of data revealed no effect of the generator exhaust on APN measurements.

\subsection{Instrumentation}

A sonic anemometer (Campbell CSAT-3) was mounted on the north tower at $z=17.7 \mathrm{~m}$ above the forest floor $(z-d=11.9 \mathrm{~m})$ and $2 \mathrm{~m}$ out from the tower into the prevailing daytime wind. The APN flux inlet was mounted $11 \mathrm{~cm}$ behind the sonic transducer heads and aligned horizontally and vertically with the center of the anemometer. Inlets for APN gradient measurements were also located along the north tower at $5.0 \mathrm{~m}$ and $1.5 \mathrm{~m}$. The three sampling lines consisted of one $9.5 \mathrm{~mm}$ OD (flux) and two $6.4 \mathrm{~mm}$ OD (gradients) PFA tubes, each $30 \mathrm{~m}$ in length with an inline 2-micron PTFE inlet filter to remove dust and insects. Filters were changed every other day for the flux line and every 6 days for the gradient lines; filter changes did not noticeably affect instrument signal. A scroll pump maintained a constant flow of $\sim 24$ slpm down the flux line and $\sim 8$ slpm down each of the gradient lines. The flux line flow was likely turbulent (Reynolds number, $R_{e} \sim 3500$ ), thus minimizing inlet damping effects on flux measurements (Lenschow and Raupach, 1991). APN losses due to thermal decomposition in the inlet lines was $<3 \%$, as estimated by dividing the plug-flow residence time in the inlets $(\sim 2 \mathrm{~s})$ by the average PAN thermal decomposition lifetime (given by the inverse of the rate constant for R-1. This was confirmed by several calibration tests that showed no detectable difference in PAN signal when adding calibration PAN gas to the beginning versus the end of the inlet lines.

Speciated APN measurements were obtained via a custom-built thermal dissociation - chemical ionization mass spectrometer (TD-CIMS) similar to that described by Wolfe et al. (2007). In brief, the technique involves thermal dissociation of APNs (Reaction R1b) followed by reaction of the acyl peroxy radicals with iodide to form carboxylate anions (Villalta and Howard, 1996; Slusher et al., 2004):

$$
\mathrm{RC}(\mathrm{O}) \mathrm{O}_{2}+\mathrm{I}^{-} \cdot\left(\mathrm{H}_{2} \mathrm{O}\right)_{n} \rightarrow \mathrm{RC}(\mathrm{O}) \mathrm{O}^{-} \cdot\left(\mathrm{H}_{2} \mathrm{O}\right)_{n}+\mathrm{IO}
$$

The product ions are then declustered and detected with a quadrupole mass spectrometer (Extrel). Based on sensitivity and background measurements, mean $1 \mathrm{~s}$ detection limits $(\mathrm{S} / \mathrm{N}=2)$ for PAN, PPN and MPAN are estimated as $6 \mathrm{pptv}, 4 \mathrm{pptv}$ and $12 \mathrm{pptv}$, respectively. Total uncertainties for single-point concentration measurements are estimated as $\pm(21 \%+3$ pptv $)$ for PAN and PPN and $\pm(31 \%+3$ pptv $)$ for MPAN (see Appendix A).

The first half of each hour was devoted to flux measurements and the second half to gradients. While sampling from the flux inlet during minutes $0-26$ of each hour, masses for PAN $(m / z=58.7)$, PPN $(m / z=72.7)$ and MPAN $(m / z=84.7)$ were monitored at $3.3 \mathrm{~Hz}$. Sonic anemometer measurements of horizontal and vertical wind speeds $(u, v, w)$ and sonic virtual temperature $\left(T_{S}\right.$, derived from the speed of sound) were simultaneously recorded on the same computer. As will be shown below, this sampling scheme was both long enough and fast enough to sufficiently capture all of the EC flux. The lower gradient inlets were sampled during minutes $30-43(5.0 \mathrm{~m})$ and $45-58(1.5 \mathrm{~m})$. The remaining portions of the hour were used for calibration and background measurements. Full mass spectra (30-200 amu) were also acquired periodically to confirm the peak center for each monitored APN and identify new peaks that may correspond to additional APN species (Fig. 1).

\subsection{Eddy Covariance}

In EC, the vertical flux of a scalar over a surface is given by the covariance of that scalar, $c$, with vertical wind velocity, $w$, 


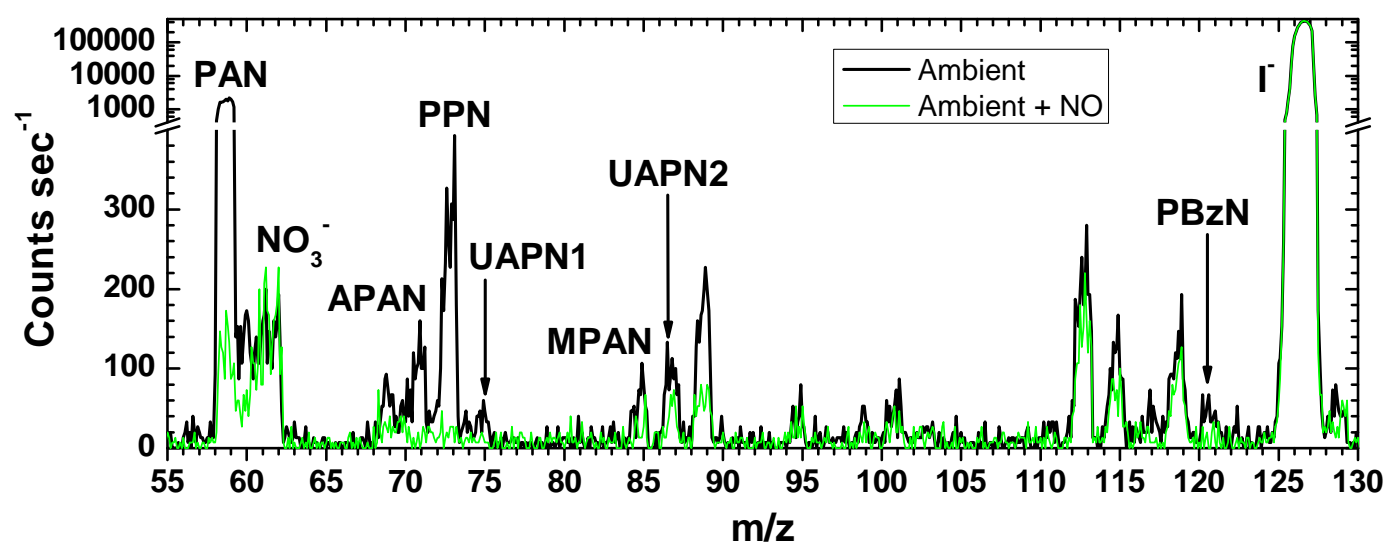

Fig. 1. Chemical ionization mass spectra acquired on the morning of day 248 ( 5 September). The solid black line represents ambient air sampled at $5.0 \mathrm{~m}$, while the thin green line is a background scan obtained directly after the sample scan by adding excess NO. Signal at the PAN peak corresponds to an ambient PAN mixing ratio of $\sim 500$ pptv. Identified peaks include PAN, PPN, MPAN, APAN $\left(R=\mathrm{CH}{ }_{2} \mathrm{CH}\right.$, $m / z=70.7), \mathrm{PBzN}\left(R=\mathrm{C}_{6} \mathrm{H}_{5}, m / z=120.7\right)$, and a set of unresolved APNs (UAPN): UAPN1 at $m / z=74.7\left(R=\mathrm{CH}_{3} \mathrm{O}\right.$ or $\left.\mathrm{HOCH}_{2}\right)$ and UAPN2 at $m / z=86.7\left(R=\mathrm{CH}_{3} \mathrm{CH}_{2} \mathrm{CH}_{2},\left(\mathrm{CH}_{3}\right)_{2} \mathrm{CH}, \mathrm{CH}_{3} \mathrm{C}(\mathrm{O}), \mathrm{HC}(\mathrm{O}) \mathrm{CH}_{2}\right.$ or $\left.\mathrm{HOCHCH}\right)$.
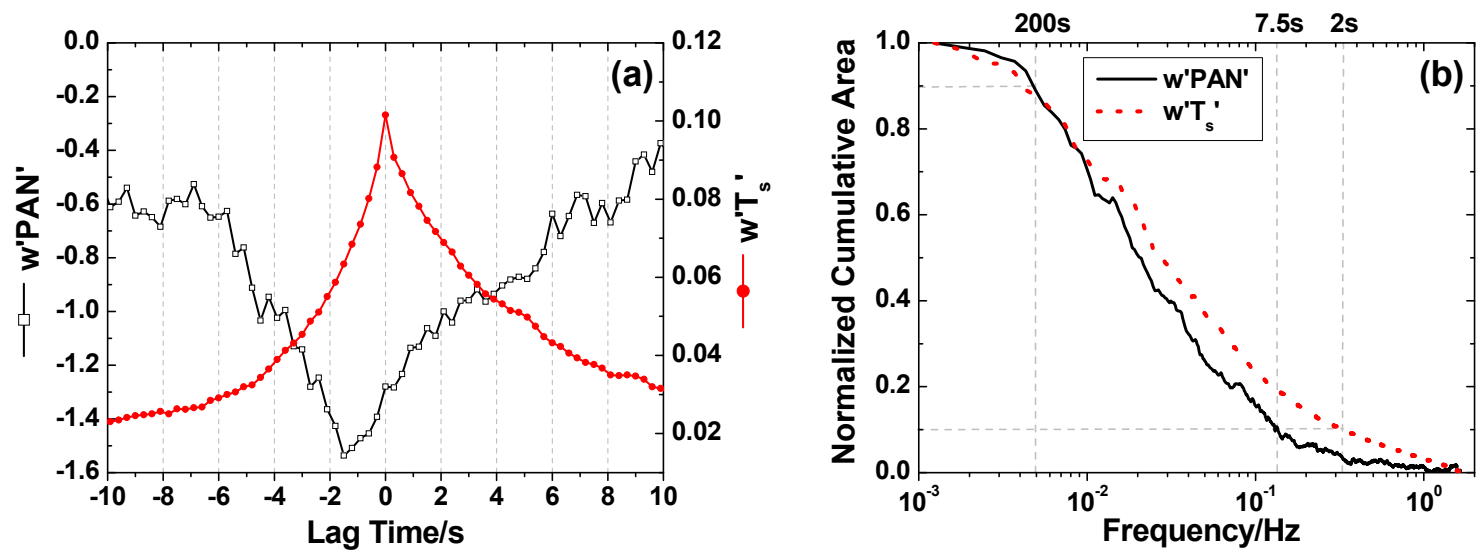

Fig. 2. (a) Representative lag-correlation plots for vertical wind speed with PAN (black line with open squares) and with sonic virtual temperature (red line with solid circles), averaged over hours 7-17 of day 264 (21 September). The location of the peaks correspond to the optimum lag times. (b) Representative cumulative area plots (ogives) for cospectra of vertical wind speed with PAN (solid black line) and with sonic virtual temperature (dotted red line), averaged over hours 7-17 of day 264 (21 September) and normalized to their maximum values. Drop lines in (b) indicate the frequencies for the 10th and 90th percentiles of cospectral power, and labels at the top denote the corresponding eddy timescales. To obtain the normalized frequency in (b), multiply by $z / \bar{U}=7.1 \mathrm{~s}$.

$F_{c}=\frac{1}{n} \sum_{i=1}^{n}\left(w_{i}-\bar{w}\right)\left(c_{i}-\bar{c}\right)=\left\langle w^{\prime} c^{\prime}\right\rangle$

where $n$ is the total number of data points in the measurement period and $\bar{w}, \bar{c}, w^{\prime}$ and $c^{\prime}$ are the mean and fluctuating components of the instantaneous measured values $w_{i}$ and $c_{i}$. $\mathrm{EC}$ is a standard technique for measurement of energy and trace gas exchange over surfaces, and details on its application may be found elsewhere (e.g. Lee et al., 2004).

For each $27 \mathrm{~min}$ flux measurement period, horizontal and vertical wind vectors were despiked and rotated into the natural wind coordinate using a two-step rotation such that $\bar{v}=\bar{w}=0$ (McMillen, 1988). APN mixing ratios were despiked with a similar algorithm (typically $<5 \%$ of data removed) and detrended using a 10-min running mean. Lagcorrelation plots were calculated for all flux periods to determine an average lag time between scalar signals and vertical wind speed, which was then applied to each flux period before calculation of the EC flux via Eq. (1). Figure 2a shows average lag-correlation plots for $\mathrm{PAN}^{\prime}$ and $T_{s}^{\prime}$ with $w^{\prime}$. Since $T_{s}^{\prime}$ and $w^{\prime}$ are measured on the same sensor, their correlation is maximized at a lag of 0 points. The $w^{\prime} \mathrm{PAN}^{\prime}$ correlation is optimized at a lag of 5 points $(-1.5 \mathrm{~s})$, in agreement with the calculated $1.9 \mathrm{~s}$ inlet tubing residence time 
minus the $0.4 \mathrm{~s}$ electronic delay in sonic anemometer measurements. The same lag was determined for $w^{\prime} \mathrm{PPN}^{\prime}$ and $w^{\prime} \mathrm{MPAN}^{\prime}$ correlations. After the lag correction, EC fluxes for PAN, PPN and MPAN were calculated as per Eq. (1), along with fluxes for momentum, $F_{\mathrm{mom}}=\left\langle u^{\prime} w^{\prime}\right\rangle$, and sensible heat, $F_{s h}=\rho c_{p}\left\langle w^{\prime} T_{s}^{\prime}\right\rangle$, where $\rho$ is air density and $c_{p}$ is the heat capacity of air at constant pressure.

Cumulative distribution plots of flux cospectra, or ogives, provide a straightforward method for identifying potential errors in measured fluxes due to spectral attenuation or other factors. Figure $2 b$ shows the cumulative contribution of all frequency components to the total fluxes of PAN and $T_{s}$ averaged over a single day. Both ogives closely approach horizontal asymptotes at the ends of the spectrum, indicating that sampling was both long enough and fast enough to capture the dominant flux-carrying eddies. The $w^{\prime} \mathrm{PAN}^{\prime}$ ogive decreases more quickly than the $w^{\prime} T_{s}^{\prime}$ ogive above $0.01 \mathrm{~Hz}$, suggesting that some PAN flux is being lost at these frequencies, or else the distribution of flux-carrying eddies is different for these two scalars (see also Fig. 3b). Sensor separation and inlet dampening errors are estimated by applying transfer functions to measured cospectra and calculating the corrected covariance (Moore, 1986; Massman, 1991); in both cases, the average PAN flux error is $<2 \%$. Flux underestimates due to instrument time response (Horst, 1997) are typically $6 \%$ for daytime measurements and $4 \%$ at night. Uncertainties in EC fluxes may also arise from random noise in concentration measurements (Lenschow and Kristensen, 1985; Ritter et al., 1990). Typical fractional uncertainties in APN fluxes due to instrument noise are $\pm 10-20 \%$ (see Appendix A). Taking into account the uncertainty in concentration measurements, spectral attenuation and instrument noise, total uncertainties in hourly EC fluxes are conservatively estimated as $\pm 40 \%$ for PAN and PPN and $\pm 50 \%$ for MPAN. Note that most of the data presented is averaged over longer timescales, where variance is dominated by atmospheric variability rather than random errors.

\subsection{Spectral analysis}

Analysis of spectra can provide further validation of EC fluxes and insight into the mechanisms controlling turbulent transport at BFRS. Figure 3a shows representative cospectra of vertical wind velocity with $T_{s}$ and PAN. Both $w^{\prime} \mathrm{PAN}^{\prime}$ and $w^{\prime} T_{s}^{\prime}$ cospectra decrease linearly throughout the inertial sub-range (above $0.003 \mathrm{~Hz}$ ), although the falloff slope, $f^{-5 / 3}$, is shallower than the $f^{-7 / 3}$ predicted by surface layer theory (Kaimal and Finnigan, 1994). Shallow cospectral slopes have been observed previously at BFRS for different micrometeorological scalar measurements (Farmer et al., 2006) and may be indicative of complex processes controlling the turbulence structure at this site, such as wake/waving turbulence production (Kaimal and Finnigan, 1994). Positive values (opposite sign from the net flux) in the highfrequency end of the $w^{\prime} \mathrm{PAN}^{\prime}$ cospectrum may also hint at
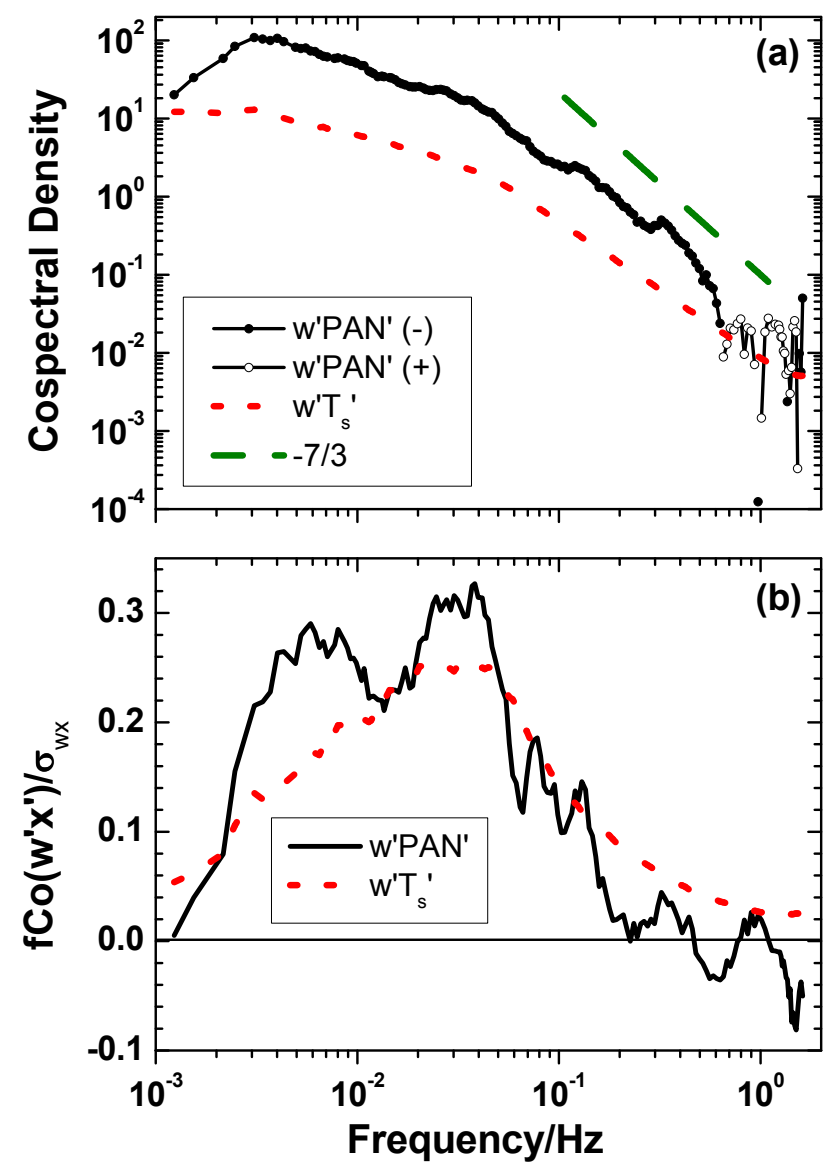

Fig. 3. (a) Averaged cospectra for vertical wind speed with PAN (solid black line with solid and open circles) and with sonic virtual temperature (dotted red line). All cospectra from hour $13(\sim 40$ cospectra in total) were averaged together, and the average cospectra were further smoothed by averaging into 200 equally-spaced logarithmic bins. Solid and open circles in the $w^{\prime} \mathrm{PAN}^{\prime}$ cospectrum denote negative and positive cospectral density, respectively. The dashed green line indicates the $-7 / 3$ slope expected for the inertial sub-range. (b) Frequency-weighted, covariance-normalized cospectra for vertical wind speed with PAN (solid black line) and with sonic virtual temperature (dotted red line), averaged as in (a). Note that absolute frequency is shown on the bottom axis of (b); the normalized frequency can be obtained by multiplying by $z / \bar{U}=7.1 \mathrm{~s}$.

intricate within-canopy activity. Intra-canopy production of PAN combined with shear or wake-generated eddies could give rise to an apparent upward flux at these frequencies, although in Fig. 3a the spectral power in this range is $<0.2 \%$ of the total covariance observed at $9.8 \mathrm{~m}$ above the canopy top.

Frequency-weighted $w^{\prime}$ PAN $^{\prime}$ cospectra (Fig. 3b) also display significant structure, with two distinct maxima. The higher-frequency maximum at $0.03 \mathrm{~Hz}$ (normalized frequency $n=0.21$ ), collocated with that of the $w^{\prime} T_{s}^{\prime}$ cospectrum, corresponds to an eddy scale of $\tau_{w} \sim 20-50 \mathrm{~s}$ and is likely dominated by shear and thermal eddies. The 


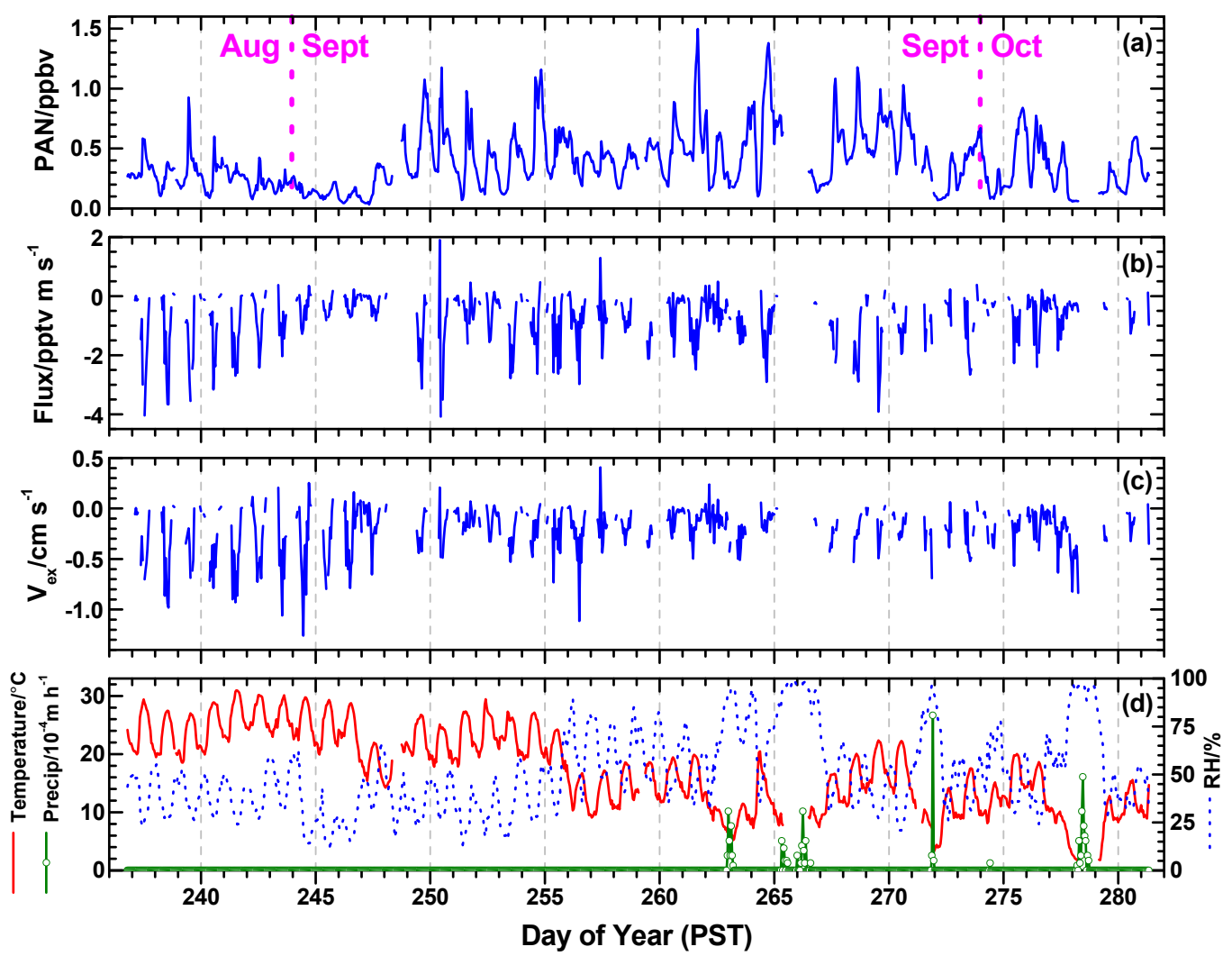

Fig. 4. Time series for (a) PAN mixing ratio, (b) PAN flux, (c) PAN exchange velocity and (d) sonic virtual temperature (solid red line), precipitation (solid dark yellow line with open circles) and relative humidity (dotted blue line). All data are averaged to an hourly time base. Missing data in (a) and (d) are due to instrument failure, while missing data in (b) and (c) are due to both instrumental issues and quality control removal protocols. Thick dotted magenta lines in (a) denote the division between months.

lower-frequency maximum at $0.006 \mathrm{~Hz}(n=0.04)$ might result from periodic sweep-ejection events, as the timescale ( $\left.\tau_{w} \sim 100-200 \mathrm{~s}\right)$ is consistent with previous observations of such behavior at BFRS (Holzinger et al., 2005). Falloff in the high-frequency end is faster for $w^{\prime} \mathrm{PAN}^{\prime}$ cospectra than $w^{\prime} T_{s}^{\prime}$ cospectra, as observed in previous measurements of PAN EC fluxes (Turnipseed et al., 2006). Since our calculations suggest that spectral attenuation has little effect on EC fluxes, we suspect that this steeper falloff is a real characteristic of APN fluxes, though a more rigorous analysis is outside the scope of the current study.

\section{Results}

\subsection{Concentrations}

Figure $4 \mathrm{a}$ shows the full time series of PAN mixing ratios measured at $17.7 \mathrm{~m}$, and Fig. 5a shows the average diurnal cycles of PAN, PPN and MPAN. Advection and photochemistry gives rise to a regular diurnal cycle that peaks around hours $14-15$, a few hours prior to the arrival of the
Sacramento urban plume (Dillon et al., 2002). This pattern is consistent with previous TD-LIF measurements of total peroxynitrates ( $\Sigma$ PNs) at BFRS, but summer 2007 mixing ratios of $\Sigma$ PNs and of PAN+PPN+MPAN are $\sim 30 \%$ lower than $\Sigma$ PNs measured in previous years (Murphy et al., 2007; Farmer and Cohen, 2008), consistent with lower average temperatures in summer 2007 (Day et al., 2008). With maximum daytime air temperatures approaching $30^{\circ} \mathrm{C}$ (Fig. 4d), PAN mixing ratios decreased to $<50$ pptv during the first 12 days of observations. The sustained period of higher temperatures likely reduced PAN in background air and decreased its lifetime in the urban plume. PAN mixing ratios increase rapidly after day 247 (4 September) due to both a drop in temperature and the arrival of a large biomass burning plume from the nearby Moonlight fire (California Department of Forestry and Fire Protection, 2008). Another notable event is the first period of rain (Fig. 4d) on days 263, 265 and 266 (20, 22 and 23 September), followed by an increased nighttime PAN minimum over the next few days.

Mixing ratios of PPN and MPAN display qualitatively similar patterns to that of PAN, with concentrations that are typically ten times lower than PAN (see Fig. 5a and Table 1). 
Table 1. Median midday (hours 10-14) APN mixing ratios, fluxes and exchange velocities.

\begin{tabular}{lccccc}
\hline APN & Conc/pptv & Flux/pptv m s & $V_{e x} / \mathrm{cm} \mathrm{s}^{-1}$ & $\begin{array}{c}V_{e x} / \mathrm{cm} \mathrm{s}^{-1} \\
(\text { Day }<256)\end{array}$ & $\begin{array}{c}V_{e x} / \mathrm{cm} \mathrm{s}^{-1} \\
(\text { Day }>256)\end{array}$ \\
\hline PAN & 391 & -1.1 & -0.3 & -0.4 & -0.2 \\
PPN & 34 & -0.2 & -0.7 & -1.3 & -0.4 \\
MPAN & 31 & -0.1 & -0.4 & -0.4 & -0.2 \\
\hline
\end{tabular}

${ }^{\mathrm{a}} 1 \mathrm{pptv} \mathrm{m} \mathrm{s}^{-1}=0.13 \mu \mathrm{mol} \mathrm{m}^{-2} \mathrm{~h}^{-1}=0.49 \mathrm{ng} \mathrm{N} \mathrm{m}^{-2} \mathrm{~s}^{-1}$.

As the precursors of these compounds are more specific than those of PAN, they do occasionally exhibit unique behavior; for example, the sudden temperature drop of $\sim 9^{\circ} \mathrm{C}$ between days 255 and 256 (12-13 September) is followed by a $50 \%$ decrease in MPAN that is less noticeable in PAN and absent in PPN (data not shown). Concentrations of biogenic VOCs, including the methacrolein precursor isoprene, also decline substantially after the temperature drop (J. Gilman and J. de Gouw, personal communication, 2008). Campaign-averaged PPN/PAN and MPAN/PAN ratios are 0.09 and 0.07, respectively.

\subsection{Fluxes}

To interpret EC fluxes, it is necessary to account for all terms in the full mass balance equation, given by

$\mathrm{F}+\mathrm{S}=\mathrm{P}+\mathrm{L}+\mathrm{E}+\mathrm{D}+\mathrm{T}$

On the left-hand side, $\mathrm{F}$ is the EC flux (i.e. turbulent transport) and S is the "storage" of a chemical below the measurement height, while the terms on the right-hand side represent vertically-integrated chemical production $(\mathrm{P})$, chemical loss (L), surface emission (E), surface deposition (D) and horizontal transport $(\mathrm{T})$. Under the assumption that we are sampling "similar" air masses over the course of the flux measurement period (a fair assumption for a remote ground site with no local sources), horizontal transport may be ignored. For APNs, emission from surfaces is also negligible. Storage, however, can be a significant fraction of the total mass balance, especially in developed tree canopies where vertical mixing is hampered by foliage or when the amplitude of the mixing ratio diel cycle is large relative to its mean value (Rummel et al., 2007). We choose to account for the storage term at the outset of our analysis, as we wish to focus only on the part of the turbulent flux that reflects physical and chemical processes. The storage term, defined as the time rate of change of the mixing ratio vertical profile, for PAN is

$\mathrm{S}=\frac{\partial}{\partial t} \int_{0}^{z}[\operatorname{PAN}](z) d z$
We evaluate this term for each hour of the measurement period using measured profiles of PAN, PPN and MPAN and add it to the EC flux to yield the storagecorrected flux. Compared to the EC flux, the storage term is typically $<25 \%$ for PAN, $<10 \%$ for PPN and $<5 \%$ for MPAN. Diel cycles are qualitatively similar for all APN storage terms, with positive values throughout the morning and early afternoon and negative values at night (Fig. 5b). Hereafter, all reported fluxes are storagecorrected, unless otherwise noted. We report fluxes in units of pptv $\mathrm{ms}^{-1}$; for depositional units, the conversion 1 pptv m s${ }^{-1}=0.13 \mu \mathrm{mol} \mathrm{m}^{-2} \mathrm{~h}^{-1}=0.49 \mathrm{ng} \mathrm{N} \mathrm{m}^{-2} \mathrm{~s}^{-1}$ is recommended.

EC fluxes of PAN, PPN and MPAN measured at BFRS (Figs. $4 \mathrm{~b}$ and $5 \mathrm{~b}$ ) are primarily downward throughout the measurement period, indicating the dominance of loss processes within the canopy. Daily maximum PAN fluxes scale with concentration (compare Fig. 4a-b), but other factors also influence APN fluxes, as evidenced by the different diurnal patterns of APN concentrations and fluxes (Fig. 5a-b). Typical midday PAN fluxes range from -1 to $-4 \mathrm{pptv} \mathrm{m} \mathrm{s}^{-1}$, while fluxes of PPN and MPAN are 50-80\% lower, consistent with their lower mixing ratios (Table 1). All fluxes decrease in magnitude at night, likely due to both reduced turbulent mixing (typical friction velocities, $u^{*}$, are $\sim 0.5 \mathrm{~m} \mathrm{~s}^{-1}$ during the day and $<0.15 \mathrm{~m} \mathrm{~s}^{-1}$ at night) and a decrease in canopy sinks, e.g. deposition or chemical loss. The storage-corrected PAN flux does not reach zero at night but maintains an average value of $-0.15 \mathrm{pptv} \mathrm{m} \mathrm{s}^{-1}$, suggesting that within-canopy losses, while diminished, are persistent throughout the night. Fluxes could not be calculated during periods of precipitation due to malfunctioning of the sonic anemometer. Other gaps in the flux time series result mainly from the implementation of quality control criteria as described in Sect. 2.3 and Appendix A. By normalizing EC fluxes to concentrations, we obtain a more direct measure of the influence of environmental and ecological parameters on surface exchange. This quantity, known as the exchange velocity,

$V_{e x}=\mathrm{F} / \bar{C}$ 

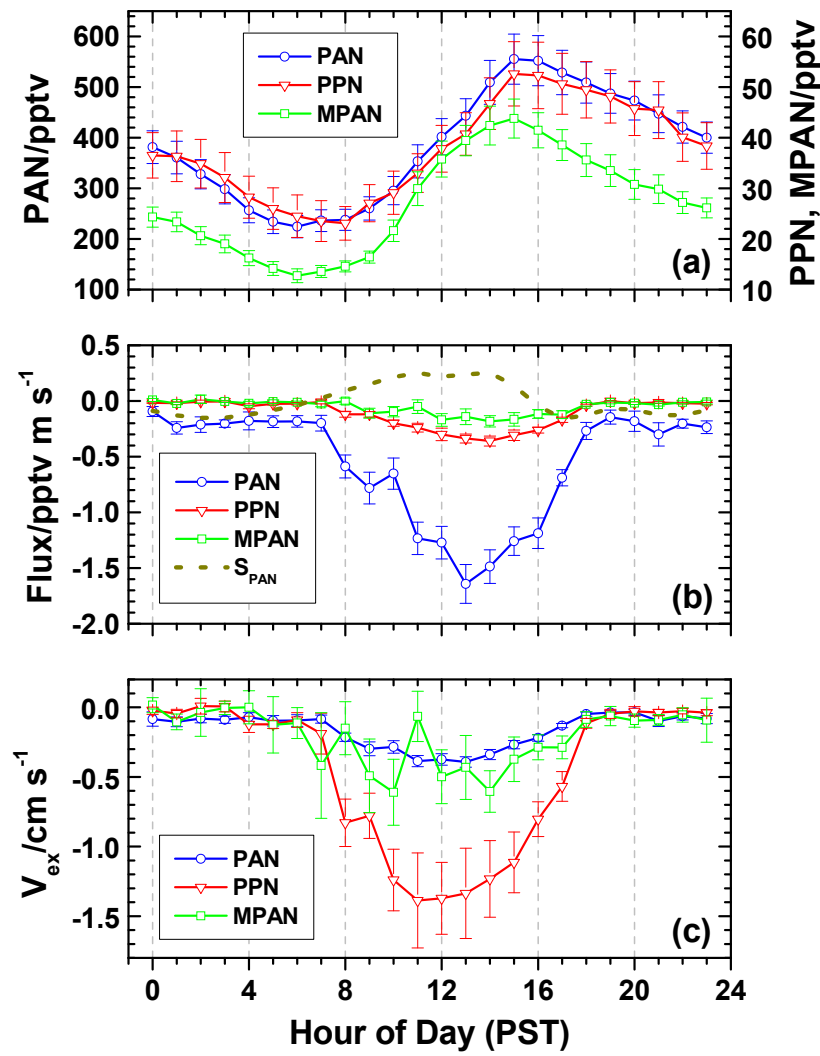

Fig. 5. Average diurnal cycles of (a) mixing ratios, (b) fluxes and (c) exchange velocities for PAN (blue circles), PPN (red triangles) and MPAN (green squares). Each symbol represents the mean of 25 to 45 hourly-averaged points, and error bars denote standard deviation of the mean. The dotted yellow line in (b) is the mean diurnal cycle of the PAN canopy storage term.

where $\bar{C}$ is the mean concentration over a single flux measurement period, is the key parameter incorporated into models of atmospheric deposition (Wesely, 1989; Wesely and Hicks, 2000). The deposition velocity, $V_{\text {dep }}$, is $-V_{e x}$. PAN exchange velocities, shown in Fig. 4c, are less variable than fluxes over the course of the campaign, although some seasonality is evident. Maximum $V_{e x}$ (PAN) is typically -0.8 to $-1.0 \mathrm{~cm} \mathrm{~s}^{-1}$ during the first 12 days but drops to $\sim 50 \%$ of this range for the remainder of the measurement period; PPN and MPAN $V_{e x}$ exhibit qualitatively similar decreases. Diurnal profiles of exchange velocities (Fig. 5c) are qualitatively similar to the flux profiles, highlighting that the magnitude of APN surface exchange, at least over the course of a single day, is not significantly influenced by the doubling of mixing ratios from early morning to late afternoon.

Unexpectedly, the diurnal maximum $V_{e x}(\mathrm{PPN})$ is roughly double that of PAN and MPAN when averaged over the entire campaign (Table 1). Examination of the full time series (not shown) reveals that this relative enhancement in $V_{e x}(\mathrm{PPN})$ is only present before the steep temperature drop on day 256 (13 September), after which $V_{e x}(\mathrm{PPN})$ is comparable to $V_{e x}(\mathrm{PAN})$. This pattern is not observed in

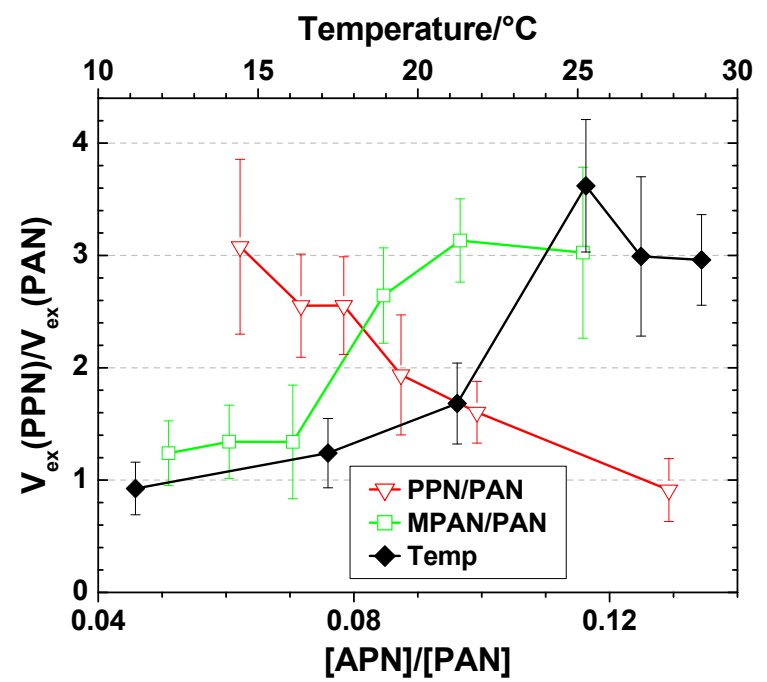

Fig. 6. Ratio of exchange velocities for PPN and PAN, binned by temperature (solid black diamonds) and concentration ratios of PPN/PAN (open red triangles) and MPAN/PAN (open green squares). Each point represents the median of 36 hourly-averaged daytime (hours 9-17) measurements, and error bars denote standard deviation of the mean. Note that the upper and lower $\mathrm{x}$-axes are independent of one another.

the ratio of $V_{e x}(\mathrm{MPAN})$ to $V_{e x}(\mathrm{PAN})$, which remains similar across the seasonal transition. Figure 6 illustrates that $V_{e x}(\mathrm{PPN})$ is most enhanced over $V_{e x}(\mathrm{PAN})$ when temperatures and MPAN/PAN ratios are high, and when PPN/PAN is low, suggesting a correlation with BVOC-dominated photochemistry.

\section{Analysis and discussion}

Many factors can influence the net flux of APNs over a forest (Eq. 2), and it is necessary to evaluate each of these contributions individually. After a comparison of our results with previous studies of APN surface exchange, we proceed with a detailed assessment of the contribution of stomatal uptake, gradients in thermal decomposition loss rates and intracanopy production to the net observed APN fluxes. All of these processes play an important role in determining the net APN exchange between the forest and the mixed layer, but the relative magnitude of each varies with season. We end with a discussion of the consequences of APN deposition for reactive nitrogen loss from the atmosphere and $\mathrm{N}$ addition to the biosphere.

\subsection{Comparison with previous work}

Virtually all previous studies of PAN surface exchange point towards uptake by plants, although the type of vegetation and environmental conditions can greatly influence the efficiency of deposition. Uptake by grasses appears to be relatively 
inefficient, with $V_{e x}$ on the order of -0.1 to $-0.3 \mathrm{~cm} \mathrm{~s}^{-1}$ (Garland and Penkett, 1976; Dollard et al., 1990; Doskey et al., 2004). Studies on herbaceous species (e.g. crops) show higher rates of PAN deposition, but the range (0 to $-0.7 \mathrm{~cm} \mathrm{~s}^{-1}$ ) is more variable across species (Hill, 1971; Okano et al., 1990; Schrimpf et al., 1996; Sparks et al., 2003). PAN transfer to deciduous and coniferous forests is typically the most efficient, with $V_{e x}<-0.5 \mathrm{~cm} \mathrm{~s}^{-1}$, in agreement with our results (Shepson et al., 1992; Sparks et al., 2003; Turnipseed et al., 2006; Farmer and Cohen, 2008). Laboratory studies have demonstrated a strong dependence of PAN uptake on light that alludes to the role of stomatal transport (Okano et al., 1990; Sparks et al., 2003). Observations of non-zero uptake at night, however, imply deposition also occurring on other surfaces, such as leaf cuticles, tree boles, soil or ground litter (Shepson et al., 1992; Schrimpf et al., 1996; McFadyen and Cape, 1999; Turnipseed et al., 2006). Our EC measurements reveal small but persistent nighttime deposition of APNs, with typical nightime $V_{e x}$ (PAN) of 0 to $-0.2 \mathrm{~cm} \mathrm{~s}^{-1}$. These values are consistent with, but slower than, previous nighttime PAN flux measurements, such as the -0.2 to $-0.6 \mathrm{~cm} \mathrm{~s}^{-1}$ observed by Turnipseed et al. (2006) with an analogous EC/TD-CIMS system over a Loblolly pine plantation or the $-0.54 \mathrm{~cm} \mathrm{~s}^{-1}$ derived from indirect techniques (Shepson et al., 1992; Schrimpf et al., 1996). Interestingly, downward nighttime PAN fluxes are significantly different from zero only after correction for storage (see Fig. 5b). While the quality control procedures should remove any spurious fluxes, EC can become unreliable at night under low-turbulence conditions; thus on nights when PAN mixing ratios decayed exponentially, we performed a pseudo-first order loss analysis (Shepson et al., 1992) as a check on our EC measurements. Assuming a nocturnal boundary layer height of $100 \mathrm{~m}$, we estimate average nighttime $V_{e x}(\mathrm{PAN})$ of -0.05 to $-0.2 \mathrm{~cm} \mathrm{~s}^{-1}$, in agreement with our EC values. While deposition is likely the dominant nighttime APN sink at BFRS, it appears to be slower than in other locations.

Only two prior studies report direct measurements of APN surface exchange via eddy covariance. Farmer and Cohen (2008) measured fluxes of speciated $\mathrm{NO}_{\mathrm{y}}$, including sum peroxy nitrates ( $\Sigma$ PNs), from June 2004 to June 2005 at BFRS. For comparison purposes, we assume that acyl peroxy nitrates measured by our TD-CIMS comprise the majority of the $\Sigma$ PNs measured by Farmer and Cohen (2008). Their wintertime measurements show downward $V_{e x}$ comparable to our late summer measurements, but they observe an efflux of $\Sigma$ PNs with noontime $V_{e x} \cong+0.7 \mathrm{~cm} \mathrm{~s}^{-1}$ during the summer. This upward flux is accompanied by simultaneous upward $\mathrm{HNO}_{3}$ fluxes, which they attribute to high photochemical production rates below the sensor height due to elevated hydroxyl radical $(\mathrm{OH})$ levels $\left([\mathrm{OH}] \sim 10^{7}\right.$ molecules $\mathrm{cm}^{-3}$ ) within the canopy. These measurements, while markedly different, are not irreconcilable with our net downward APN fluxes from summer 2007. As noted in Sect. 3.1, available data indicate significant differences between summer 2007 and previous years at BFRS. Cooler temperatures in 2007 could lead to reduced biogenic emissions and thus less photochemical APN production throughout the forest, as evidenced by our observation of $30 \%$ lower APN concentrations and $15 \%$ less ozone relative to previous years. The canopy structure is also more mature in the current study, with denser foliage and more exposed plant surfaces that may enhance deposition and hinder escape of reactive species from the canopy airspace. Dissimilarities in experimental design may also be a factor, such as different measurement heights $(14.3 \mathrm{~m}$ vs. $17.7 \mathrm{~m})$. Although both measurements were taken within the "constant flux layer" above the canopy (Kaimal and Finnigan, 1994), the assumption of constant flux is only strictly valid for conserved quantities (i.e. heat and water vapor) and not necessarily true for reactive chemical species like APNs. A detailed comparison of our spectra with those of Farmer et al. (2006) and Farmer and Cohen (2008), although outside the scope of the current work, might afford more insight on this issue, as would future simultaneous measurements of fluxes at multiple heights. Numerical modeling of chemistry and diffusion in the canopy would also provide a framework for exploring these differences.

Turnipseed et al. (2006) used EC/TD-CIMS to measure speciated APN fluxes above a North Carolina Loblolly pine forest for 12 days in July 2003. They report downward fluxes of PAN, PPN and MPAN that maximize at midday with a diurnal profile that is qualitatively similar to ours. Their measurements show comparable deposition velocities for all three APNs, in contrast to our observations of significantly larger PPN deposition velocities at BFRS during late August and early September. Although their PPN and MPAN deposition velocities are more variable than ours, a genuine difference in the factors controlling APN exchange may exist between these two sites. Turnipseed et al. (2006) also observe slight enhancements in $V_{e x}$ (PAN) when canopy elements are wet due to rain or dew formation; unfortunately, failure of the sonic anemometer during wet periods prevent us from exploring such effects in the current data set.

To provide a gauge for the magnitude of APN flux at BFRS, we may compare $V_{e x}(\mathrm{PAN})$ with the exchange velocity of ozone $\left(\mathrm{O}_{3}\right)$, also measured during BEARPEX. Mean ratios of $V_{e x}\left(\mathrm{O}_{3}\right) / V_{e x}(\mathrm{PAN})$ are $\sim 0.8$ during the day and $\sim 2$ at night, consistent with previous observations and estimates (Hill, 1971; Garland and Penkett, 1976; Shepson et al., 1992; McFadyen and Cape, 1999; Doskey et al., 2004; Turnipseed et al., 2006). Caution must be exercised when interpreting such comparisons, as the mechanisms driving above-canopy fluxes of APNs and $\mathrm{O}_{3}$ could be quite different. Previous work at BFRS has shown that downward $\mathrm{O}_{3}$ fluxes derive from both deposition and chemical reactions with BVOC emissions, with the latter being the dominant in-canopy $\mathrm{O}_{3}$ sink during the summer (Kurpius and Goldstein, 2003; Goldstein et al., 2004). As we will show, chemical processes can also strongly influence APN fluxes. 


\subsection{Resistance model}

The diurnal shape of APN fluxes (Fig. 5b-c) suggests a connection to sunlight-mediated processes. Many factors could contribute to such a profile, including turbulence intensity, air temperature, stomatal activity, biogenic emissions and photochemistry. To explore the mechanisms controlling APN surface exchange, we employ a resistance model analysis as applied by Turnipseed et al. (2006); this approach is based on the widely accepted parameterization of surface deposition in chemistry-transport models (Wesely, 1989; Wesely and Hicks, 2000). Physical transfer of a molecule from the atmosphere to the surface is assumed to occur through a series of barriers, each with a characteristic resistance. The total transfer resistance, $R$, is defined as the negative inverse of the measured exchange velocity:

$R=-1 / V_{e x}=R_{a}+R_{b}+R_{c}$

The aerodynamic resistance, $R_{a}$, is related to turbulent transport of a molecule from the mixed layer to the surface and can be parameterized as

$R_{a}=\frac{\bar{U}(z-d)}{u_{*}^{2}}-\frac{\Psi_{H}(\zeta)-\Psi_{M}(\zeta)}{k u_{*}}$

where $\bar{U}(z-d)$ is the average wind speed at height $z-d$ (the top of the surface layer), $u_{*}=\left|\left\langle u^{\prime} w^{\prime}\right\rangle\right|^{1 / 2}$ is the friction velocity, $k \sim 0.4$ is von Karman's constant, $\zeta=(z-d) / L$ is the stability parameter, $L=-u_{*}^{3} \bar{T}_{S} / \mathrm{kg}\left\langle w^{\prime} T_{s}^{\prime}\right\rangle$ is the Obukhov length, and $\Psi_{H}(\zeta)$ and $\Psi_{M}(\zeta)$ are the integrated stability corrections for sensible heat and momentum, respectively (Dyer, 1974; Arya, 1988). The laminar sublayer resistance, $R_{b}$, is associated with molecular diffusion through the thin viscous layer surrounding individual surface elements (e.g. pine needles) and can be estimated by

$R_{b}=\frac{v}{D_{x} u_{*}}\left[\frac{100 l u_{*}}{(L A I)^{2} v}\right]^{1 / 3}$

where $\nu=1.7 \times 10^{-5} \mathrm{~m}^{2} \mathrm{~s}^{-1}$ is the pressure-corrected kinematic viscosity of air, $D_{x}$ is the pressurecorrected diffusion coefficient for a particular molecule $\left(D_{\text {PAN }}=1.0 \times 10^{-5} \mathrm{~m}^{2} \mathrm{~s}^{-1}\right.$, Wesely, 1989), LAI $=5.1 \mathrm{~m}^{2} \mathrm{~m}^{-2}$ is the leaf area index for BFRS, and $1=0.001 \mathrm{~m}$ is the "characteristic length scale" of the canopy surface elements, roughly the thickness of a pine needle (Jensen and Hummelsh $\varnothing \mathrm{j}, 1995,1997) . \quad R_{c}$, the surface resistance, is calculated by subtracting the contribution from $R_{a}$ and $R_{b}$ from the observed total resistance, i.e. $R_{c}=\mathrm{R}-\left(R_{a}+R_{b}\right)$. For vegetative systems, $R_{c}$ can be further divided into stomatal $\left(R_{s t}\right)$ and non-stomatal $\left(R_{n s}\right)$ surface components that act in parallel:

$\frac{1}{R_{c}}=\frac{1}{R_{s t}}+\frac{1}{R_{n s}}$
The non-stomatal component includes contributions from uptake to other surfaces (e.g. leaf cuticles, bark, soil) as well as turbulent transfer to the lower canopy and ground (Wesely, 1989). This model assumes that downward fluxes are purely the result of surface deposition. We disregard the potential confounding influence of upward chemical fluxes in the following analysis, with the admission that the observed PAN exchange velocity may be a lower limit to the actual deposition rate (see Sect. 4.6). The analysis will focus on PAN fluxes, as these constitute $\sim 80 \%$ of the total APN flux.

Both $R_{a}$ and $R_{b}$ exhibit a strong diurnal cycle with minimum values during the day, due largely to their inverse dependence on $u^{*}$. Average summer midday $R_{a}$ and $R_{b}(\mathrm{PAN})$ at BFRS are $\sim 6 \mathrm{~s} \mathrm{~m}^{-1}$ and $14 \mathrm{~s} \mathrm{~m}^{-1}$, respectively, consistent with previous estimates for coniferous forests (Jensen and Hummelshøj, 1995; Pilegaard et al., 1995; Sievering et al., 2001; Pryor and Klemm, 2004; Turnipseed et al., 2006). The quantity $R_{a}+R_{b}$ represents the minimum resistance against surface loss, i.e. if $R_{c}=0$, then every collision with the surface is a loss of the gas-phase molecule. Similarly, the maximum possible deposition velocity is given by $V_{\max }=\left(R_{a}+R_{b}\right)^{-1}$. For the current study, $R_{a}+R_{b}$ is $<15 \%$ of $R$, which is typically 100 to $400 \mathrm{~s} \mathrm{~m}^{-1}$ during the day, and daytime $V_{\max }$ is typically $2-5 \mathrm{~cm} \mathrm{~s}^{-1}$ for PAN. Transfer of APNs into the canopy is thus limited not by turbulent or molecular diffusion, but by actual uptake at the surface and/or other physicochemical processes.

\subsection{Stomatal contribution to APN fluxes}

Uptake of APNs by plant stomata represents a direct pathway for transfer of atmospheric nitrogen to the biosphere, and laboratory studies have suggested that this pathway is the dominant depositional sink for PAN over vegetative surfaces (Okano et al., 1990; Sparks et al., 2003). The maximum possible contribution of stomatal activity to the surface exchange may be estimated by calculating the resistance against transfer of water across the stomata and correcting for slower diffusion of PAN, i.e. $R_{s t}(\mathrm{PAN})=\left(D_{\mathrm{H}_{2} \mathrm{O}} / D_{\mathrm{PAN}}\right) R_{s t}\left(\mathrm{H}_{2} \mathrm{O}\right)$, where $D_{\mathrm{H}_{2} \mathrm{O}}=2.27 \times 10^{-5} \mathrm{~m}^{2} \mathrm{~s}^{-1}$ (Monteith and Unsworth, $1990)$ and $D_{\text {PAN }}=0.89 \times 10^{-5} \mathrm{~m}^{2} \mathrm{~s}^{-1}$ (Wesely, 1989). Stomatal resistance was computed using both the PenmanMonteith equation (Monteith and Unsworth, 1990) and the leaf boundary water vapor gradient approach (Thom, 1975), both of which rely on measurements of canopy-scale water vapor fluxes. Both methods yield comparable results, in agreement with recent work that has shown the two to be mathematically equivalent (Gerosa et al., 2007). Given the dry summer conditions at BFRS, we assume that the abovecanopy water vapor flux is primarily due to evapotranspiration from vegetation, except for periods during or after precipitation events (see Fig. 4d). The latter have been removed from the dataset before calculation of stomatal fluxes, along with early morning data where dew may have formed on 


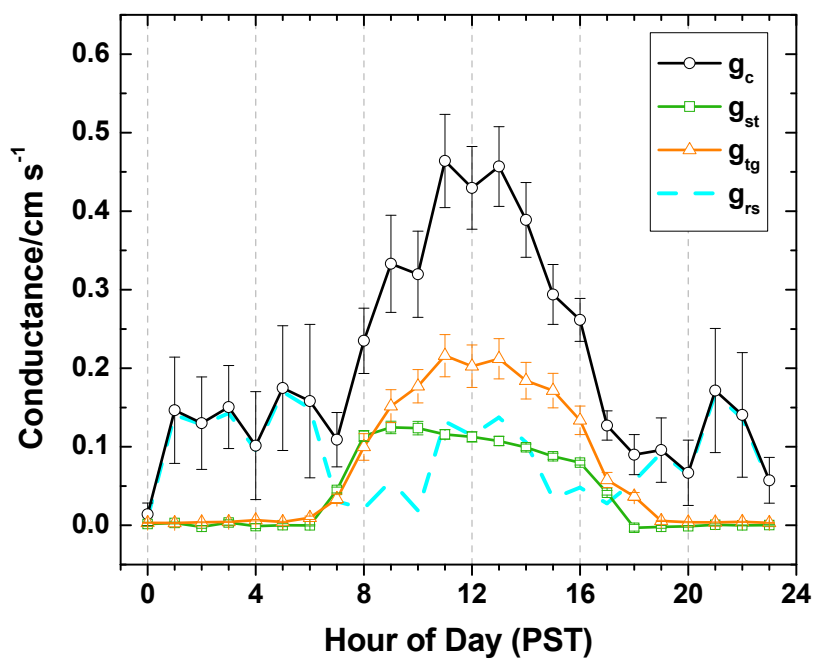

Fig. 7. Average diurnal cycles of total PAN surface conductance (black circles), PAN stomatal conductance (green squares), PAN thermochemical gradient conductance (red triangles) and residual conductance (dashed cyan line). Each symbol represents the mean of 25 to 45 hourly-averaged points, and error bars denote standard deviation of the mean.

surfaces. As the surface resistances add in parallel (Eq. 8), it is more appropriate to compare surface conductances (e.g. $\left.g_{s t} \equiv 1 / R_{s t}\right)$.

Figure 7 compares the mean diurnal cycle of the stomatal conductance, $g_{s t}$, with that of the total surface conductance $\left(g_{c}\right)$ as estimated from Eqs. (5-8). Stomatal conductance peaks in the mid-morning hours and drops steadily throughout the day, consistent with estimates from other studies of water-stressed canopies (Jensen and Hummelshøj, 1995; Gerosa et al., 2007), and the magnitude is comparable to what has been observed in previous years at BFRS (Kurpius et al., 2003). Stomatal uptake can account for $\sim 29 \%$ of the daytime PAN surface conductance on average, though a plot of $g_{s t}(\mathrm{PAN})$ against $g_{c}(\mathrm{PAN})$ (Fig. 8) reveals that the ratio of $g_{s t} / g_{c}$ can range from $\sim 1$ to $<0.1$. Turnipseed et al. (2006) observed similar behavior (compare our Fig. 8 with their Fig. 9) and surmised that the extra conductance derived from uptake to other surfaces, particularly plant cuticles. Earlier theoretical work by Doskey et al. (2004) indicates that cuticular uptake of PAN should be minimal, although it is conceivable that PAN thermal decomposition followed by reaction of peroxyacetyl radical $\left(\mathrm{PA} \equiv \mathrm{H}_{3} \mathrm{CC}(\mathrm{O}) \mathrm{O}_{2}\right)$ with cuticular surfaces could be significantly faster than direct uptake of PAN.

\subsection{Thermochemical gradient fluxes}

Figure 8 demonstrates that higher values of $g_{c}(\mathrm{PAN})$ are associated with increased temperatures, suggesting that thermal decomposition may play a role in the loss of APNs to the canopy. At least two mechanisms could contribute to this

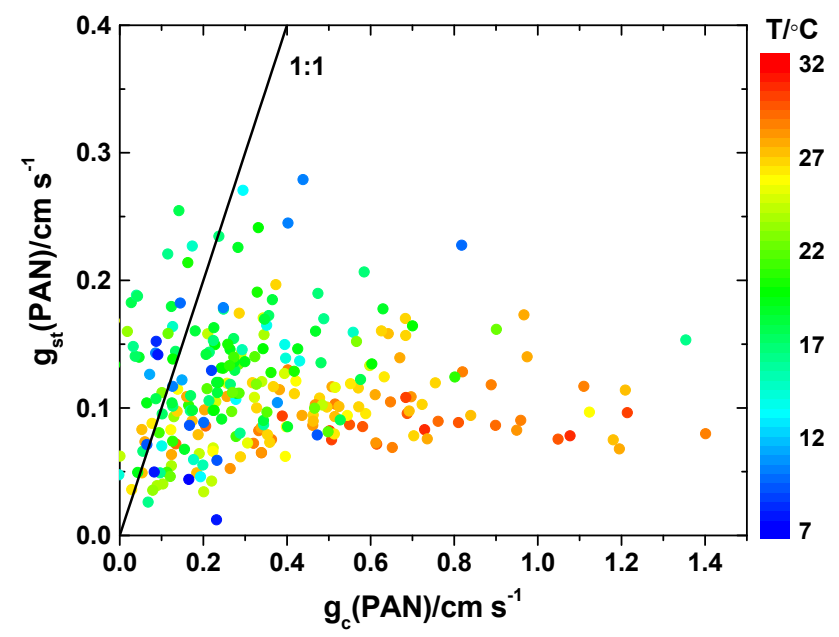

Fig. 8. Scatter plot of PAN stomatal conductance versus total surface conductance, color-mapped by air temperature. Only daytime points (hours 9-17) are shown, and data has been removed for days after precipitation events. The 1:1 correspondence line is shown for reference.

dependence: 1) vertical thermochemical gradients in PAN, and 2) faster deposition of PA relative to PAN. The lifetime of PAN with respect to thermal decomposition is ultimately determined by its thermal dissociation rate and the fate of the PA radical:

$$
\begin{aligned}
& \mathrm{PA}+\mathrm{NO}_{2} \rightarrow \mathrm{PAN} \\
& \mathrm{PAN} \rightarrow \mathrm{PA}+\mathrm{NO}_{2} \\
& \mathrm{PA}+\mathrm{NO} \rightarrow \mathrm{NO}_{2}+\text { products } \\
& \mathrm{PA}+\mathrm{XO}_{2} \rightarrow \text { products }
\end{aligned}
$$

In Reaction $\mathrm{R} 4, \mathrm{XO}_{2} \equiv \mathrm{HO}_{2}+\mathrm{RO}_{2}$, where $\mathrm{RO}_{2}$ represent organic peroxy radicals. Losses of PAN via photolysis or reaction with $\mathrm{OH}$ are negligible relative to thermal decomposition at altitudes below $7 \mathrm{~km}$ (Talukdar et al., 1995). The steady state PA mixing ratio from the above reactions is given by

$$
[\mathrm{PA}]=\frac{k_{1 \mathrm{~b}}[\mathrm{PAN}]}{k_{1 \mathrm{a}}\left[\mathrm{NO}_{2}\right]+\mathrm{k}_{3}[\mathrm{NO}]+\mathrm{k}_{4}\left[\mathrm{XO}_{2}\right]}
$$

where $k_{i}$ is the rate constant for reaction $i$. Mixing ratios of PAN, $\mathrm{NO}_{2}$ and $\mathrm{HO}_{2}$ were measured during BEARPEX. Using these with measured ozone and $\mathrm{NO}_{2}$ photolysis rates estimated from the TUV Radiation Model (NCAR, 2008), $\mathrm{NO}$ can be calculated from the steady state equation

$[\mathrm{NO}]=\frac{\mathrm{j}_{\mathrm{NO}_{2}}\left[\mathrm{NO}_{2}\right]}{k_{\mathrm{O}_{3}+\mathrm{NO}\left[\mathrm{O}_{3}\right]}+k_{\mathrm{XO}_{2}+\mathrm{NO}_{2}\left[\mathrm{XO}_{2}\right]}}$

Vertical temperature profiles measured during BEARPEX reveal large thermal gradients throughout the canopy due to strong surface heating (note that the BFRS canopy is young 


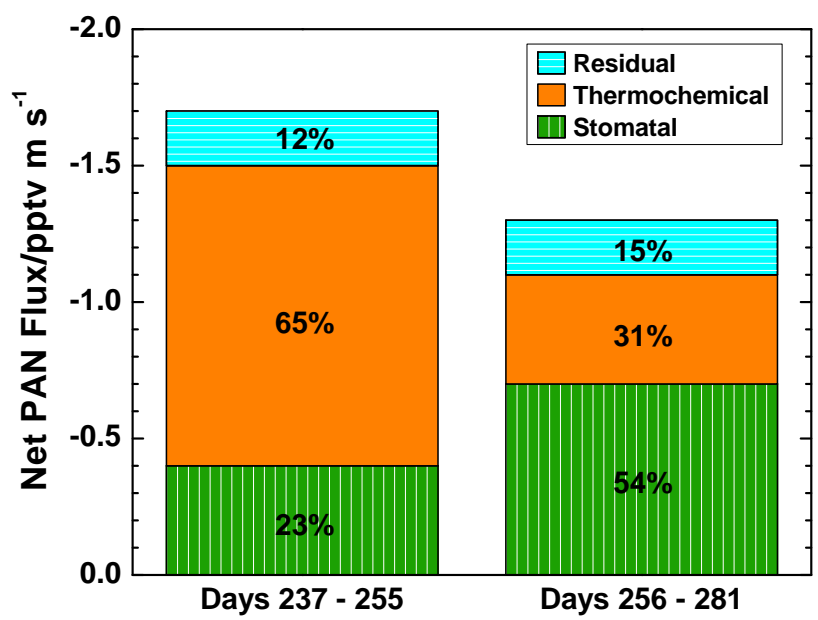

Fig. 9. Mean midday (hours 10-14) net PAN flux for warm (left) and cool (right) periods. Fluxes are further divided into contributions from stomatal uptake (bottom green bars), thermochemical gradients (middle red bars) and residual flux (top cyan bars).

and fairly open). As suggested by Doskey et al. (2004), enhanced thermal decomposition (TD) near the surface could lead to a gradient in PAN concentrations and thus a downward flux of PAN. The flux due to this thermochemical gradient, $\mathrm{F}_{t g}$, can be calculated from the vertical profile of PAN and its thermal decomposition rate (Doskey et al., 2004):

$\mathrm{F}_{t g}=-\int_{z_{0}}^{z} \frac{[\mathrm{PAN}](\mathrm{z})}{\tau_{t d}(z)} d z$

Here, $\tau_{t d}$ is the pseudo-first order lifetime of PAN with respect to TD as derived from Reaction (R1a, R1b) and Eq. (9):

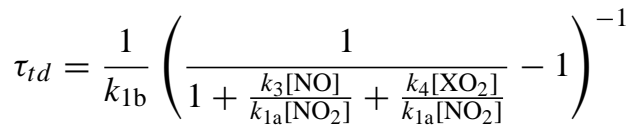

The vertical profile of $\tau_{t d}$ is dependent on gradients of temperature, $[\mathrm{NO}] /\left[\mathrm{NO}_{2}\right]$ and $\left[\mathrm{XO}_{2}\right] /\left[\mathrm{NO}_{2}\right]$; for this calculation, we assume the latter two ratios are constant with height. Although this is likely not the case in the real atmosphere, this approximation likely has a minimal impact as sensitivity tests indicate that the temperature gradient is the primary factor controlling $\mathrm{F}_{t g}$. Equation (11) was evaluated numerically from $z_{0}=1.5 \mathrm{~m}$ to $z=17.7 \mathrm{~m}$ for each hour of the flux measurement period using vertical profiles of PAN (measurements at $1.5 \mathrm{~m}, 5.0 \mathrm{~m}$ and $17.7 \mathrm{~m}$ ) and temperature (measurements at $3.0 \mathrm{~m}, 4.9 \mathrm{~m}, 8.75 \mathrm{~m}$ and $12.5 \mathrm{~m}$ ), single-height observations of $\left[\mathrm{HO}_{2}\right]\left(\sim\left[\mathrm{XO}_{2}\right] / 2\right.$, Mihelcic et al., 2003) and $\left[\mathrm{NO}_{2}\right]$ (measurement heights $5-7 \mathrm{~m}$ ), and $[\mathrm{NO}] /\left[\mathrm{NO}_{2}\right]$ estimated from Eq. (10). Average calculated midday $[\mathrm{NO}] /\left[\mathrm{NO}_{2}\right]$ is $\sim 0.27$, consistent with previous estimates for BFRS (Kurpius and Goldstein, 2003). To compensate for poor dataset overlap, $\left[\mathrm{HO}_{2}\right]$ and $\left[\mathrm{NO}_{2}\right]$ were averaged to a diurnal time base and used to "gap fill" times when these measurements were missing from the full data set. Note that we do not account here for attenuated diffusion and mixing within the canopy, though this effect should be minor as measured midday vertical wind profiles are log-linear throughout the canopy, suggesting that surface winds easily penetrate to the forest floor. Due to a lack of measurements, we also do not consider TD between $1.5 \mathrm{~m}$ and the ground, which could result in an underestimation of the thermochemical gradient flux (potentially by a factor of two to three, see Sect. 4.6) as this region is likely warmer and contains higher NO mixing ratios than the middle and upper canopy airspace. Note that this differs from the analysis of Turnipseed et al. (2006), who argue that the timescale of thermal decomposition $\left(\tau_{t d}\right)$ is too slow compared to the turbulent diffusion timescale $\left(\tau_{w}\right)$ to generate a perceivable chemical gradient, i.e. that the "flux divergence" due to PAN chemistry is negligible. We propose that the difference in loss rates between the surface and aloft should also be considered, as TD may be an important component of the surface layer sink, irrespective of the turbulence timescale.

Figure 7 shows the diurnal average of the effective thermochemical gradient conductance $\left(g_{t g}=-\mathrm{F}_{t g} / \bar{C}_{\mathrm{PAN}}\right)$. Comparison between $g_{t g}$ and $g_{c}$, while not strictly correct, is admissible since typically $R_{c} \gg\left(R_{a}+R_{b}\right)$. The thermochemical gradient conductance exhibits the expected diurnal shape with an average maximum of $\sim 0.2 \mathrm{~cm} \mathrm{~s}^{-1}$, slightly higher than the stomatal conductance. Depending on temperature, $\mathrm{F}_{t g}$ can account for 30-65\% of the net flux (see Fig. 9). Enhanced TD of PAN in the forest also represents an in-canopy source of $\mathrm{NO}_{2}$, which would presumably affect the vertical $\mathrm{NO}_{2}$ flux. With a typical midday summer $2005 \mathrm{NO}_{2}$ concentration of 300 pptv (Farmer and Cohen, 2008), an exchange velocity that is equal but opposite in sign to $g_{t g}(\mathrm{PAN})$ would give rise to an $\mathrm{NO}_{2}$ flux of +0.6 pptv m s${ }^{-1}$, which is $\sim 10 \%$ of the net upward $\mathrm{NO}_{2}$ flux measured at BFRS in previous years (Farmer and Cohen, 2008).

Surface deposition of PA generated via Reaction (R1b) would be observed as a downward flux of PAN. Increasing temperatures will shift the equilibrium of Reaction (R1a, $\mathrm{R} 1 \mathrm{~b}$ ) towards PA and $\mathrm{NO}_{2}$, and a sufficiently fast flux of PA could induce a perceived temperature dependence on the surface conductance of PAN. For median noontime mixing ratios of $[\mathrm{PAN}]=391 \mathrm{pptv},\left[\mathrm{NO}_{2}\right]=347 \mathrm{pptv},\left[\mathrm{XO}_{2}\right]=44 \mathrm{pptv}$ and $[\mathrm{NO}]=94$ pptv, Eq. (12) gives an estimated $[\mathrm{PA}] \sim 1 \mathrm{pptv}$ due to TD of PAN. The maximum deposition rate for PA, given by $V_{\max }=\left(R_{a}+R_{b}(\mathrm{PA})\right)^{-1}$, is $\sim 4.7 \mathrm{~cm} \mathrm{~s}^{-1}$ at noon, yielding a maximum PA flux of $\sim 0.05$ pptv $\mathrm{m} \mathrm{s}^{-1}$. At best, PA deposition is $<5 \%$ of total PAN flux at $17.7 \mathrm{~m}$ and thus cannot explain the temperature dependence of $g_{c}$. Our analysis implies that a considerable fraction of the downward PAN flux observed over the forest is not due to deposition and thus is not a direct pathway for atmosphere-biosphere nitrogen exchange. The sum of downward fluxes from stomatal uptake and thermal decomposition can account at most 
Table 2. Calculation of upward and downward APN flux components.

\begin{tabular}{|c|c|c|c|c|}
\hline Species & Conc/pptv ${ }^{\mathrm{a}}$ & Net Flux $\left(V_{e x}\right)^{\mathrm{a}, \mathrm{b}}$ & Downward Flux $\left(V_{e x}\right)^{\mathrm{b}}$ & Upward Flux $\left(V_{e x}\right)^{\mathrm{b}}$ \\
\hline PAN & 301 & $-1.1(-0.4)$ & $-3.9(-1.3)^{\mathrm{c}}$ & $+2.8(+0.9)$ \\
\hline PPN & 23 & $-0.3(-1.3)$ & $-0.3(-1.3)^{\mathrm{c}}$ & $0.0(0.0)^{\mathrm{C}}$ \\
\hline MPAN & 34 & $-0.2(-0.4)$ & $-0.4(-1.3)^{\mathrm{c}}$ & $+0.2(+0.9)$ \\
\hline PAN+PPN+MPAN & 357 & $-1.6(-0.4)$ & $-4.6(-1.3)^{\mathrm{c}}$ & $+3.0(+0.8)$ \\
\hline$\Sigma \mathrm{PNs}^{\mathrm{d}}$ & 758 & $+5(+0.7)$ & $-8(-1.1)$ & $+13(+1.8)$ \\
\hline
\end{tabular}

a Median of data from hours 10-14, prior to day 256.

${ }^{\mathrm{b}}$ Flux/pptv m s${ }^{-1}\left(V_{\text {ex }} / \mathrm{cm} \mathrm{s}^{-1}\right)$.

c Assumed value (see text).

${ }^{\mathrm{d}}$ Farmer and Cohen (2008), mean noontime values.

for $85-90 \%$ of the net PAN flux (see Fig. 9), leaving a small portion of "unidentified" or residual flux $\left(g_{r s}=g_{c}-\left(g_{s t}+g_{t g}\right)\right.$, see Fig. 7). As suggested by previous studies, this flux may be due to non-stomatal uptake to other surfaces, including leaf cuticles, tree boles and branches, soil, and ground litter (Shepson et al., 1992; Turnipseed et al., 2006). Indeed, uptake to these surfaces would be consistent with the observation of non-zero PAN conductance at night, when stomata are closed and thermochemical gradients are negligibly small owing to low $[\mathrm{NO}] /\left[\mathrm{NO}_{2}\right]$ and $\left[\mathrm{XO}_{2}\right] /\left[\mathrm{NO}_{2}\right]$ (see Eq. 12).

\subsection{Seasonality of net APN fluxes}

Falling temperatures on day 256 (13 September, Fig. 4d) brought noticeable changes in the processes controlling chemical composition over the forest, providing an opportunity to examine the influence of the summer - fall transition on APN fluxes. Figure 9 shows mean midday (hours 10-14) net PAN fluxes for both warm (before day 256) and cool (after day 256) periods, further divided into stomatal, thermochemical gradient and residual flux components. Stomatal flux is calculated by multiplying the stomatal conductance for each hour by the PAN mixing ratio for that hour. The residual flux is the difference between the stomatal and thermochemical gradient components and the net observed flux. Net midday PAN flux slows by $\sim 25 \%$ between the warm and cool periods despite a $30 \%$ increase in PAN mixing ratios, and the relative importance of individual flux components shifts markedly. The thermochemical gradient flux decreases by almost a factor of three between the warm and cool periods even though daytime temperature gradients of $\sim 0.2^{\circ} \mathrm{C} \mathrm{m}^{-1}$ were typical throughout the entire measurement period, highlighting that $\mathrm{F}_{t g}$ is sensitive to both the vertical temperature gradient and the absolute temperature. Stomatal conductance increases by $33 \%$ with the onset of wetter conditions as previously observed at BFRS (Kurpius et al., 2003), becoming the dominant contributor to downward PAN flux during the cool period. Both the absolute value $\left(-0.2\right.$ pptv m s$\left.^{-1}\right)$ and the fraction $(12-15 \%)$ of residual flux remain fairly constant between the two periods, consistent with the supposition that this flux represents dry deposition to non-stomatal surfaces. If, however, an upward chemical flux masks a larger gross downward flux of PAN as we speculate below, the surface removal process may remain largely unidentified.

\subsection{Differences in PAN, MPAN, and PPN exchange veloc- ities}

The observation that the midday deposition velocity of PPN is 3 times that of PAN and MPAN during the warm period (Table 1 and Fig. 6) suggests that either 1) net downward fluxes of PAN and MPAN are less negative due to an upward flux that is non-existent or smaller for PPN, or 2) there is an in-canopy loss process that acts preferentially on PPN and cannot be explained by stomatal uptake or thermochemical gradients. The latter explanation seems less likely, as we expect depositional and chemical losses (i.e. thermal decomposition) of APNs to be similar since their physical and chemical properties are comparable (Roberts and Bertman, 1992; Grosjean et al., 1994a, b; Kames and Schurath, 1995), excepting the relatively fast MPAN+OH reaction (Orlando et al., 2002). The net flux of a reactive species above a forest can be represented as the sum of fluxes from a number of processes that vary with height, including deposition, chemical production and chemical loss (Eq. 2). Enhanced chemical production of PAN and MPAN within the canopy due to higher concentrations of $\mathrm{OH}$ and/or biogenic VOC (BVOC), as suggested by Farmer and Cohen (2008), could add a positive component to the net observed flux of these species. Chemical fluxes due to APN production should be driven by the product of vertical concentration profiles of $\mathrm{OH}$ and $\mathrm{VOC}$ precursors (e.g. acetaldehyde, methacrolein, propanal, etc.). The precursors of PPN are primarily anthropogenic and thus should not be enhanced in the canopy.

Under this assumption, we estimate the upward and downward components of the fluxes of PAN and MPAN using median midday (hours 10-14) values for mixing ratios and fluxes measured before day 256; Table 2 summarizes these calculations. If the upward flux of PPN is negligible, then 
the PPN $V_{e x}$ of $-1.3 \mathrm{~cm} \mathrm{~s}^{-1}$ represents the maximum possible downward velocity for APN loss to the canopy. Multiplying by PAN and MPAN mixing ratios gives gross downward fluxes of -3.9 and $-0.4 \mathrm{pptv} \mathrm{m} \mathrm{s}^{-1}$, respectively. Balancing the flux budget with the net observed fluxes then requires upward PAN and MPAN fluxes of +2.8 and $+0.2 \mathrm{pptv} \mathrm{m} \mathrm{s}^{-1}$. In comparison with the results of Farmer and Cohen (2008), also shown in Table 2, the downward component of our exchange velocity $\left(-1.3 \mathrm{~cm} \mathrm{~s}^{-1}\right)$ is close to their $-1.1 \mathrm{~cm} \mathrm{~s}^{-1}$. Their downward $V_{e x}$ is likely a lower limit, as it is estimated by scaling their wintertime $\Sigma \mathrm{PN} V_{e x}$ by the ratio of summer to winter $u^{*}$ and thus does not account for enhanced summertime processes like thermochemical gradient fluxes. Our upward component $\left(+0.8 \mathrm{~cm} \mathrm{~s}^{-1}\right)$ is about half of theirs $\left(+1.8 \mathrm{~cm} \mathrm{~s}^{-1}\right)$, in line with the supposition that dissimilarities in the net observed fluxes at BFRS between the summers of 2004 and 2007 are a consequence of differences in photochemical conditions.

In our earlier discussion, we required an unidentified sink that was $12 \%$ of the net flux during the warm period to balance the net PAN flux budget (i.e. assuming zero upward flux). If, however, an upward chemical flux masks a gross

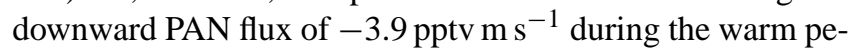
riod (Table 2), then our current estimates of stomatal uptake and thermal decomposition would only be able to explain $\sim 38 \%$ of the actual downward flux, leaving $62 \%$ unidentified. Moreover, the strength of this unidentified sink must decrease strongly across the transition from the warm to cool period (see Tables 1, 2 and Fig. 6). An underestimate in $\mathrm{F}_{t g}$ could potentially explain some of the missing gross downward flux. The thermochemical gradient flux naturally exhibits a strong seasonal dependence (Fig. 9), and as noted in Sect. 4.4, the magnitude of our estimated $\mathrm{F}_{t g}$ is likely a lower limit since temperatures and $[\mathrm{NO}] /\left[\mathrm{NO}_{2}\right]$ may be higher near the ground than at the lowest temperature measurement height $(3.0 \mathrm{~m})$. For example, we can explain $\sim 90 \%$ of the gross downward PAN flux with thermochemical gradients if we assume, as an extreme upper limit, that air temperature increases by $20^{\circ} \mathrm{C}$ (Goldstein, unpublished data) and $[\mathrm{NO}] /\left[\mathrm{NO}_{2}\right]$ doubles (Gao et al., 1991) between $3.0 \mathrm{~m}$ and $0.01 \mathrm{~m}$ above the surface. This would also imply a thermochemical $\mathrm{NO}_{2}$ gradient flux of +3 pptv m s${ }^{-1}-$ almost half of the net upward $\mathrm{NO}_{2}$ flux observed by Farmer and Cohen (2008), but only $\sim 11 \%$ of the $27 \mathrm{pptv} \mathrm{m} \mathrm{s}^{-1}$ they require to balance the $\mathrm{NO}_{\mathrm{y}}$ flux budget.

The decreased strength of this unidentified sink during the cool period must also be accompanied by a decrease in the upward chemical flux of PAN and MPAN to reconcile the relatively small changes in their $V_{e x}$ between the warm and cool periods. Figure 6 shows that the ratio $V_{e x}(\mathrm{PPN}) / V_{e x}(\mathrm{PAN})$ approaches 1 with decreasing MPAN/PAN and increasing PPN/PAN, marking a shift away from BVOC-dominated photochemistry. Mixing ratios of speciated BVOC and their oxidation products - precursors for PAN and MPAN - decreased by $65-90 \%$ between the warm and cool period ( $\mathrm{J}$.
Gilman and J. de Gouw, personal communication, 2008) owing to temperature-dependent emissions and oxidation chemistry (Schade et al., 1999; Day et al., 2008). A number of parameters are influenced by the sharp temperature shift on day 256, making it difficult to pinpoint a causal relationship for variations in $V_{e x}(\mathrm{PPN}) / V_{e x}(\mathrm{PAN})$. Nevertheless, these results support our hypothesis that local intra-canopy BVOC chemistry causes an upward component to the fluxes of PAN and MPAN, which in turn raises their $V_{e x}$ relative to that of PPN.

If an upward chemical flux is not present, then stomatal uptake and thermochemical gradients are able to account for almost all of the observed PAN flux, but we are left without a viable explanation for the large PPN $V_{e x}$ observed during the warm period. Thus, our interpretation of the depositional contribution to APN fluxes is dependent on the magnitude of the chemical production term in the mass balance equation (Eq. 2). Ideally, the APN production term could be calculated directly from measured vertical profiles of $\mathrm{HO}_{\mathrm{x}}\left(\equiv \mathrm{OH}+\mathrm{HO}_{2}+\mathrm{RO}_{2}\right), \mathrm{NO}_{\mathrm{x}}, \mathrm{APNs}$ and VOC precursors; however, these observations are not available in the current dataset, and we are not able to definitively conclude on this matter. Regardless, our analysis supports the notion of within-canopy APN production and suggests complex vertical structure of atmospheric chemistry and composition within the forest.

\subsection{Consequences of APN deposition}

Under colder conditions, deposition can begin to compete with thermal decomposition as a sink for APNs (McFadyen and Cape, 1999; Turnipseed et al., 2006). The total daily losses of PAN due to deposition and thermal decomposition are respectively given by

$L_{\text {dep }}=-\int_{24 \mathrm{~h}} \frac{\mathrm{F}_{\mathrm{PAN}}}{h_{B L}} d t$
$L_{\text {chem }}=\int_{24 \mathrm{~h}} k_{t d}[\mathrm{PAN}] d t$

where $k_{t d}=1 / \tau_{t d}$ (Eq. 12) and $h_{B L}$ is the mixed layer height, assumed to be $\sim 800 \mathrm{~m}$ during the day and $\sim 100 \mathrm{~m}$ at night (Seaman et al., 1995; Dillon et al., 2002). Note that Eq. (13) is an upper limit for the true surface loss as it assumes that the PAN flux is entirely depositional. We ignore the possibility of faster gross PAN deposition and upward chemical flux here, as we wish to assess the net effect of surface/canopy PAN losses on the composition of the mixed layer. Running these calculations for each day of the campaign, we find that $L_{\text {dep }} / L_{\text {chem }}$ is $\sim 0.03$ on average during the warm period but increases to $\sim 0.21$ during the cool period, or $\sim 0.15$ if we remove the contribution of thermochemical gradients to the net PAN flux. By rearranging and substituting Eq. (4) into Eq. (13) and drawing an analogy to Eq. (14), we can define a pseudo-first order lifetime of PAN with respect to deposition:

$\tau_{\text {dep }} \cong 1 / k_{\text {dep }} \cong h_{B L} / V_{e x}$ 
This equation is reminiscent of the "boundary-layer budget" approach used by Shepson et al. (1992) to derive nighttime PAN fluxes. Typical values of $\tau_{\text {dep }}$ for PAN ranged from 3-5 days during BEARPEX, suggesting that depositional losses can significantly compete with chemical losses $\left(L_{\text {dep }} / L_{\text {chem }} \geq 1\right)$ at temperatures below $\sim 4^{\circ} \mathrm{C}$. For polluted regions in northern latitudes or during the winter, deposition could thus become the primary sink for APNs.

Transfer of atmospheric nitrogen to forested ecosystems in California is typically dominated by wet and dry deposition of nitric acid $\left(\mathrm{HNO}_{3}\right)$, as well as particulate nitrate $\left(\mathrm{NO}_{3}^{-}\right)$and ammonium $\left(\mathrm{NH}_{4}^{+}\right)$(Bytnerowicz and Fenn, 1996). To estimate the importance of APNs as a source of $\mathrm{N}$ to the biosphere, we use Eq. (13) to compare the total daily flux of APNs and $\mathrm{HNO}_{3}$ to the forest, the latter of which was also measured via eddy covariance during BEARPEX2007 (J. Crounse and P. Wennberg, personal communication, 2008). Removing the contribution of thermochemical gradients from the net sum APN flux and assuming that the remaining flux represents dry deposition, we find total APN deposition to be $\sim 4 \%$ of daily $\mathrm{HNO}_{3}$ deposition. If the gross downward sum APN flux is actually $-4.6 \mathrm{pptv} \mathrm{m} \mathrm{s}^{-1}$ $\left(0.16 \mathrm{nmol} \mathrm{m}^{-2} \mathrm{~s}^{-1}\right.$, Table 2) and is entirely depositional except for the $\mathrm{F}_{t d}$ contribution (Sect. 4.4) - we estimate that APN deposition could be as much as $19 \%$ of dry $\mathrm{HNO}_{3}$ deposition during the summer, at the high end of previous estimates (Sparks et al., 2003). Note that this is likely an upper limit, as intra-canopy production may also perturb $\mathrm{HNO}_{3}$ canopy exchange such that the gross $\mathrm{HNO}_{3}$ deposition may be larger than that inferred from observed EC fluxes. Moreover, we might expect this fraction to decrease somewhat under more typical photochemical conditions (i.e. warmer temperatures) due to higher $\mathrm{HNO}_{3}$ and lower APN mixing ratios (Day et al., 2008). As the influence of intra-canopy production on above-canopy APN and $\mathrm{HNO}_{3}$ fluxes remains uncertain, we leave the range of potential APN contribution to the $\mathrm{N}$ deposition budget at $4-19 \%$.

\section{Conclusions}

Eddy covariance measurements over a Ponderosa pine forest from late summer to early fall indicate net downward fluxes of PAN, PPN and MPAN, with magnitudes comparable to what has been previously reported in the literature. Analysis of PAN fluxes with a standard resistance model reveals that loss to the canopy is not restricted by turbulent or molecular diffusion, suggesting a surface-limited process; however, stomatal uptake is not sufficient to explain the magnitude of observed net fluxes, and evidence points toward a temperature-dependent process. Gradients in the PAN thermal decomposition rate can explain a significant fraction of the net downward PAN flux, especially when daytime temperatures exceed $20^{\circ} \mathrm{C}$. The combination of stomatal uptake and thermochemical gradients explains $85-90 \%$ of the net
PAN flux, but may only explain $38 \%$ of the gross downward PAN flux during the first half of the campaign if intracanopy PAN production contributes an upward flux as suggested by the observed higher exchange velocity of PPN relative to that of PAN and MPAN. The distribution of withincanopy sources and sinks that contribute to above-canopy APN fluxes changes considerably between summer and fall, with higher stomatal uptake and less influence from thermochemical gradients and inferred in-canopy production during the second, cooler half of the campaign.

The physical and chemical processes that occur within a forested ecosystem are intimately linked to regional photochemistry, and much work remains to acquire a full understanding of the vertical structure of emissions, deposition, transport and chemistry near the surface. Future investigations must continue to focus on detailed characterization of the vertical profiles of VOC, speciated $\mathrm{NO}_{\mathrm{y}}$ and $\mathrm{HO}_{\mathrm{x}}$, which may influence observed fluxes. For reactive species like APNs, it is critical to quantitatively constrain the role of in-canopy production and yet-unidentified sources or sinks within the canopy, as these processes ultimately determine the degree to which APN deposition impacts the budgets of atmospheric $\mathrm{NO}_{\mathrm{y}}$ and biospheric fixed N. For example, while net loss of APNs to the canopy can compete with thermal decomposition as an $\mathrm{NO}_{\mathrm{y}}$ sink under colder conditions $\left(T<4^{\circ} \mathrm{C}\right)$, our analysis suggests that $25-65 \%$ of the observed net APN flux is due to thermal decomposition gradients and thus does not represent an $\mathrm{NO}_{\mathrm{y}}$ loss during summer. Moreover, the combination of the potential for upward APN fluxes driven by intra-canopy chemistry and the indirect nature of our inferred thermochemical gradient flux can further confound such estimates. If in-canopy chemistry does not cause an upward APN flux, and our inferred thermochemical gradient fluxes are approximately correct, then APN dry deposition only contributes $4 \%$ of the atmospheric fixed $\mathrm{N}$ source to the biosphere at BFRS. On the other hand, if in-canopy chemical production causes an upward flux of $3-13$ pptv m s$^{-1}$, as previous observations (Farmer and Cohen, 2008) and our constrained estimates suggest, then the gross downward flux of APNs, if predominantly depositional, could constitute as much as $19 \%$ of the atmospheric fixed $\mathrm{N}$ source to the canopy. Improperly accounting for the dominant PAN loss process or incorrectly partitioning a potential $20 \%$ of the dry-depositing fixed $\mathrm{N}$ may skew predictions of future changes in air quality and the terrestrial carbon cycle. Flux divergence measurements and computational modeling of the vertical structure of chemistry and composition within the canopy will be required to provide closure on these problems. 


\section{Appendix A}

\section{Methods}

\section{A1 TD-CIMS}

Speciated APN measurements were obtained via a custombuilt thermal dissociation - chemical ionization mass spectrometer (TD-CIMS) similar to that described by Wolfe et al. (2007). Air is sub-sampled at $2.0 \mathrm{slpm}$ from one of the three inlet lines into a $19 \mathrm{~cm}$ length of $1 / 2^{\prime \prime}$ OD PFA tubing heated to $180^{\circ} \mathrm{C}$, where APNs thermally dissociate into $\mathrm{NO}_{2}$ and acyl peroxy radicals (Reaction R1b) with $>95 \%$ efficiency. The pressure drop down the sampling lines maintains the TD inlet at $\sim 325$ Torr; laboratory tests and model calculations indicate that this pressure drop does not affect instrument performance. The hot sample gas then passes through a critical orifice into an ion-molecule reaction region held at 60 Torr, where acyl peroxy radicals react with iodide to form carboxylate anions (Villalta and Howard, 1996; Slusher et al., 2004):

$$
\mathrm{RC}(\mathrm{O}) \mathrm{O}_{2}+\mathrm{I}^{-} \cdot\left(\mathrm{H}_{2} \mathrm{O}\right)_{n} \rightarrow \mathrm{RC}(\mathrm{O}) \mathrm{O}^{-} \cdot\left(\mathrm{H}_{2} \mathrm{O}\right)_{n}+\mathrm{IO}
$$

Iodide ions are generated by flowing 2.5 slpm UHP nitrogen over a methyl iodide $\left(\mathrm{CH}_{3} \mathrm{I}\right.$, Acros) permeation tube held at $45-50^{\circ} \mathrm{C}$ followed by a ${ }^{210} \mathrm{Po} \alpha$-particle ionizer (NRD). After a reaction time of $\sim 64 \mathrm{~ms}$, the reaction mixture passes through another orifice into a collisional dissociation chamber held at 1.3 Torr, where a static electric field of $90 \mathrm{~V} \mathrm{~cm}^{-1}$ facilitates the breakup of water-ion clusters via collisions with bath gas and directs ions through a third critical orifice into a differentially-pumped mass spectrometry chamber. An RF-only octopole ion guide focuses the ions through a final orifice into the quadrupole region for mass selection and detection (Extrel).

\section{A2 Sensitivity and background determination}

Hourly instrument calibrations were achieved by standard addition of $\sim 220$ pptv PAN to sample air just upstream of the heated inlet. PAN was generated by an acetone-nitric oxide photolysis source (Warneck and Zerbach, 1992; Wolfe et al., 2007), which has an efficiency for conversion of NO to PAN of $93 \pm 3 \%$ as determined by comparison with similar PAN sources at the National Oceanographic and Atmospheric Administration's Earth System Research Laboratory (NOAAESRL) (J. Roberts and F. Flocke, personal communication, 2007) and at the University of Washington, Bothell (E. Fischer, D. Reidmiller and D. Jaffe, personal communication, 2008). Calibration spans from 0 to 1 ppbv were also performed periodically during the campaign by addition of PAN to a flow of humidified nitrogen ( $\mathrm{RH} \sim 50 \%$ ). Calibration curves were linear throughout the span range but consistently exhibited a non-zero intercept of $\sim 190$ counts $^{-1}$, which was subtracted from the calibration signal before calculation of instrument sensitivity. Average sensitivity to PAN during the measurement period was $4.7 \pm 1.5$ counts $\operatorname{pptv}^{-1} \mathrm{~s}^{-1}$ (mean $\pm 1 \sigma$ ). Short-term variations in sensitivity were associated with temperature fluctuations of the trailer housing the instrument. The average variability between adjacent calibrations was less than $10 \%$, indicating that calibrations were sufficiently frequent to capture changes in sensitivity. In CIMS, calibration constants are typically assumed to be similar between a family of compounds, and previous work has shown this to be true for most APNs with the exception of MPAN (Slusher et al., 2004). Post-campaign calibrations done at NOAA-ESRL confirmed that our TD-CIMS is equally sensitive to PAN, PPN and APAN, but less sensitive to MPAN by a factor of 4.3 . Thus, the PAN sensitivity was applied to all raw APN signals to yield concentrations, and the MPAN signal was further corrected for reduced sensitivity.

Backgrounds were determined by addition of $25 \mathrm{ppmv}$ NO to the sample stream, which titrates peroxy radicals before ionization. NO additions were done once per hour for each inlet. As shown in Fig. 1, APN backgrounds were sometimes significant; for example, the background at $m / z=58.7$ could be as much as $5-10 \%$ of the total PAN signal. In contrast, cooling the heated inlet to room temperature (eliminating APN dissociation) or passing sample gas through a $180^{\circ} \mathrm{C}$ stainless steel tube filled with stainless steel wool (destroying peroxy radicals via surface reactions) gave background signals approaching those obtained when sampling pure $\mathrm{N}_{2}\left(<15\right.$ counts s $\left.{ }^{-1}\right)$. We favor the NO-titration method to provide the most accurate estimate of the background due to the greater possibility for unknown interferences to the APN signals in a VOC-rich forest environment that may also be destroyed on hot stainless steel tubing. Based on sensitivity and background measurements, mean 1-s detection limits $(\mathrm{S} / \mathrm{N}=2)$ for PAN, PPN and MPAN are estimated as $6 \mathrm{pptv}, 4 \mathrm{pptv}$ and $12 \mathrm{pptv}$, respectively. Total uncertainties for single-point concentration measurements are estimated as $\pm(21 \%+3$ pptv) for PAN and PPN and $\pm(31 \%+3$ pptv $)$ for MPAN.

\section{A3 Eddy covariance}

For each 27 min flux measurement period, horizontal and vertical wind vectors were despiked and rotated into the natural wind coordinate using a two-step rotation such that $\bar{v}=\bar{w}=0$ (McMillen, 1988). Despiking was accomplished by first removing the largest spikes by inspection. Then, a 30-point $(\sim 10 \mathrm{~s})$ running mean and standard deviation $(\sigma)$ was used to remove points outside of a window defined by a (mean $\pm 3 \sigma$ ) window. This method gave less false spike detections than more sophisticated despiking algorithms (Højstrup, 1993), and the fraction of despiked points was typically $\ll 1 \%$. APN mixing ratios were despiked with a similar algorithm (typically $<5 \%$ of data removed) and detrended using a 10-min running mean. The 
selected running mean time window was sufficiently long to remove advective changes in mean mixing ratios without affecting turbulent fluxes, as the characteristic eddy scales contributing to APN fluxes were much smaller than 10 min (see Fig. 2b). Lag-correlation plots were calculated for all flux periods to determine an average lag time between scalar signals and vertical wind speed, which was then applied to each flux period before calculation of the EC flux via Eq. (1). Figure 2a shows average lag-correlation plots for PAN' and $T_{s}^{\prime}$ with $w^{\prime}$. Since $T_{s}^{\prime}$ and $w^{\prime}$ are measured on the same sensor, their correlation is maximized at a lag of 0 points. The $w^{\prime} \mathrm{PAN}^{\prime}$ correlation is optimized at a lag of 5 points $(-1.5 \mathrm{~s})$, in agreement with the calculated $1.9 \mathrm{~s}$ inlet tubing residence time minus the $0.4 \mathrm{~s}$ electronic delay in sonic anemometer measurements. The same lag was determined for $w^{\prime} \mathrm{PPN}^{\prime}$ and $w^{\prime} \mathrm{MPAN}^{\prime}$ correlations. After the lag correction, EC fluxes for PAN, PPN and MPAN were calculated as per Eq. (1), along with fluxes for momentum, $\mathrm{F}_{\mathrm{mom}}=\left\langle u^{\prime} w^{\prime}\right\rangle$, and sensible heat, $\mathrm{F}_{s h}=\rho c_{p}\left\langle w^{\prime} T_{s}^{\prime}\right\rangle$, where $\rho$ is air density and $c_{p}$ is the heat capacity of air at constant pressure.

Several data quality filters were applied to the derived fluxes. Orientation of the sonic anemometer relative to mean winds was assessed by inspection of rotation angles calculated during mapping of wind vectors into the natural wind coordinate. Flux data was removed when the mean horizontal wind direction fell within the sector where the sampling tower or anemometer boom could potentially disturb the airflow. The angle required to align the vertical wind vector to give a mean vertical wind speed of zero (the "tilt angle") was typically $<5^{\circ}$ but could become large at night when turbulence was low. To minimize the potential errors (Foken and Wichura, 1996; Lee et al., 2004), time periods with tilt angles $>5^{\circ}$ were filtered from the data set. EC fluxes were also checked for stationarity by dividing each $27 \mathrm{~min}$ flux period into five $5.4 \mathrm{~min}$ periods, calculating the EC flux for each smaller period, and comparing the average to the EC flux for the full $27 \mathrm{~min}$ period. If these were not within $\pm 30 \%$ of each other (Foken and Wichura, 1996),

$$
\left|1-\frac{\left\langle w^{\prime} c^{\prime}\right\rangle_{5.4 \min }}{\left\langle w^{\prime} c^{\prime}\right\rangle_{27 \text { min }}}\right|>0.3
$$

the flux was assumed to be non-stationary and removed from the dataset. For APN fluxes, $95 \%$ of daytime data and $74 \%$ of nighttime data were stationary under these criteria. Sensible heat fluxes were $95 \%$ (day) and 60\% (night) stationary, while momentum fluxes were $86 \%$ (day) and 54\% (night) stationary. The lower percentage of stationary points at night is due to stable stratification of the nocturnal boundary layer and low-speed, intermittent nighttime winds. After application of all quality filters to APN fluxes, $74 \%$ of daytime data and $39 \%$ of nighttime data remained.

Instrument configuration and sampling strategies can lead to spectral attenuation of the measured covariance, causing underestimation of fluxes. Low-frequency attenuation stems from insufficiently long sampling times or improper detrending, while high-frequency attenuation can result from sensor separation, damping of concentration fluctuations due to diffusion-related "smearing" in inlet lines and limited instrument time response. Figure $2 \mathrm{~b}$ shows the cumulative contribution of all frequency components to the total fluxes of PAN and $T_{s}$ (also known as ogive plots), averaged over a single day. Both ogives closely approach horizontal asymptotes at the ends of the spectrum, indicating that sampling was both long enough and fast enough to capture the dominant flux-carrying eddies. The $w^{\prime} \mathrm{PAN}^{\prime}$ ogive decreases more quickly than the $w^{\prime} T_{s}^{\prime}$ ogive above $0.01 \mathrm{~Hz}$, suggesting that some PAN flux is being lost at these frequencies, or else the distribution of flux-carrying eddies is different for these two scalars (see also Fig. 3b).

Sensor separation errors can be estimated by applying a transfer function to measured cospectra and calculating the corrected covariance (given as the area under the cospectrum). The transfer function is

$\operatorname{Tr}_{s}(f)=\exp \left(-9.9\left(\frac{f s}{\bar{U}}\right)^{1.5}\right)$

where $f$ is frequency, $s$ is sensor separation $(11 \mathrm{~cm})$ and $\bar{U}$ is average wind speed (Moore, 1986). Errors resulting from inlet dampening may be estimated by the same method with another transfer function,

$T r_{d}(f)=\exp \left(-4 \pi^{2} f \Lambda L a / u^{2}\right)$

where $\Lambda$ is the "attenuation coefficient" ( $\sim 5$ for $\left.R_{e} \sim 3500\right)$, $L$ is the inlet length $(30.5 \mathrm{~m})$, a is the inlet inner radius $(0.65 \mathrm{~cm})$ and $u$ is the linear flow rate $\left(\sim 150 \mathrm{~m} \mathrm{~s}^{-1}\right)$ (Massman, 1991). For both sensor separation and inlet dampening, average PAN flux errors are $<2 \%$. Flux underestimates due to instrument time response can be approximated by

$\frac{\mathrm{F}_{\text {meas }}}{\mathrm{F}_{\text {true }}}=\frac{1}{1+2 \pi\left(\tau_{c} / \tau_{w}\right)}$

(Horst, 1997). The instrument time constant $\left(\tau_{c}=0.4 \mathrm{~s}\right)$ is estimated from the TD-CIMS PAN signal response when switching between measurement modes (i.e. background to ambient and calibration to ambient). The integral turbulence timescale, $\tau_{w}$, is the timescale of dominant flux-carrying eddies and corresponds to the peak in the frequency-weighted cospectra (see Fig. 3b). For APNs, $\tau_{w}$ is typically $40 \mathrm{~s}$ during the day and $65 \mathrm{~s}$ at night, giving average flux underestimates of $6 \%$ and $4 \%$, respectively. Maximum underestimates during high-turbulence periods ( $\tau_{w} \sim 20 \mathrm{~s}$ ) were $12 \%$. Due to the uncertainty in determining $\tau_{w}$ for a single $27 \mathrm{~min}$ flux period, these corrections are not explicitly applied to EC fluxes but are included in the total flux uncertainty. 
Uncertainties in EC fluxes may also arise from random noise in concentration measurements. The variance in a flux measurement due to instrument noise is given by (Lenschow and Kristensen, 1985; Ritter et al., 1990)

$$
\sigma_{\mathrm{inst}}^{2} \cong \frac{\sigma_{w}^{2} \sigma_{n}^{2} \Delta t}{T}
$$

Here, $T$ is the averaging period $(27 \mathrm{~min}), \Delta t$ is the sampling interval $(0.3 \mathrm{~s})$, and the $\sigma^{2}$ variances are for vertical wind speed $(w)$ and instrument noise $(n)$. For the TD-CIMS, instrument noise is described by the Poisson variance $\sigma_{n} \cong \sqrt{\bar{S}}$, where $\bar{S}$ is the average signal. Normalization by the instrument sensitivity gives $\sigma_{n}$ in concentration units. Typical fractional uncertainties in APN fluxes due to instrument noise $\left(\sigma_{\text {inst }} / \mathrm{F}\right)$ are $\pm 10-20 \%$. Taking into account the uncertainty in concentration measurements, spectral attenuation and instrument noise, total uncertainties in hourly EC fluxes are conservatively estimated as $\pm 40 \%$ for PAN and PPN and $\pm 50 \%$ for MPAN. Note that most of the data presented below is averaged over longer timescales, where variance is dominated by atmospheric variability rather than random errors.

Acknowledgements. The authors thank J. Mao, Z. Chen, X. Ren and $\mathrm{B}$. Brune for providing $\mathrm{HO}_{\mathrm{x}}$ measurements, J. Gilman and J. de Gouw for VOC measurements, J. Crounse and P. Wennberg for $\mathrm{HNO}_{3}$ flux data and permeation tube designs, and D. Farmer and I. Faloona for their comments on the manuscript and helpful discussion on eddy covariance and spectral analysis. We also thank P. Wooldridge for help with sonic anemometer measurements, J. Roberts, F. Flocke, E. Fischer, D. Reidmiller and D. Jaffe for assistance with instrument calibration, BFRS staff for their logistical expertise and Sierra Pacific Industries for providing the property to conduct this research. This work was largely supported by a National Science Foundation grant ATM-0633897. G. Wolfe acknowledges support from NASA Earth Systems Science Fellowship NNG-05GP64H.

Edited by: J. Lelieveld

\section{References}

Arya, S. P.: Introduction to Micrometeorology, Academic Press, San Diego, CA, USA, 1988.

Bauer, M. R., Hultman, N. E., Panek, J. A., and Goldstein, A. H.: Ozone deposition to a ponderosa pine plantation in the Sierra Nevada Mountains (CA): A comparison of two different climatic years, J. Geophys. Res., 105, 22123-22136, 2000.

Brown, S. S., Dibb, J. E., Stark, H., Aldener, M., Vozella, M., Whitlow, S., Williams, E. J., Lerner, B. M., Jakoubek, R., Middlebrook, A. M., DeGouw, J. A., Warneke, C., Goldan, P. D., Kuster, W. C., Angevine, W. M., Sueper, D. T., Quinn, P. K., Bates, T. S., Meagher, J. F., Fehsenfeld, F. C., and Ravishankara, A. R.: Nighttime removal of $\mathrm{NO}_{\mathrm{x}}$ in the summer marine boundary layer, Geophys. Res. Lett., 31, L07108, doi:10.1029/2004GL019412, 2004.
Bytnerowicz, A. and Fenn, M. E.: Nitrogen deposition in California forests: a review, Environ. Pollut., 92(2), 127-146, 1996.

California Department of Forestry and Fire Protection (CDF): 2007 Fire Incidents, online http://cdfdata.fire.ca.gov, last access: 14 April 2008, 2008.

Cleary, P. A., Wooldridge, P. J., Millet, D. B., McKay, M., Goldstein, A. H., and Cohen, R. C.: Observations of total peroxy nitrates and aldehydes: measurement interpretation and inference of OH radical concentrations, Atmos. Chem. Phys., 7, 19471960, 2007, http://www.atmos-chem-phys.net/7/1947/2007/.

Day, D. A., Wooldridge, P. J., and Cohen, R. C.: Observations of the effects of temperature on atmospheric $\mathrm{HNO}_{3}, \sum \mathrm{ANs}, \sum \mathrm{PNs}$, and $\mathrm{NO}_{\mathrm{x}}$ : evidence for a temperature-dependent $\mathrm{HO}_{\mathrm{x}}$ source, Atmos. Chem. Phys., 8, 1867-1879, 2008, http://www.atmos-chem-phys.net/8/1867/2008/.

Dillon, M. B., Lamanna, M. S., Schade, G. W., Goldstein, A., and Cohen, R. C.: Chemical evolution of the Sacramento urban plume: Transport and oxidation, J. Geophys. Res., 107(D5), 4045, doi:10.1029/2001JD000969, 2002.

Dollard, G. J., Jones, B. M. R., and Davies, T. J.: Dry deposition of $\mathrm{HNO}_{3}$ and PAN, A.E.R.E. Rep. R13780, Harwell Lab., Oxfordshire, UK, 1990.

Doskey, P. V., Kotamarthi, R. V., Fukui, Y., Cook, D. R., Breitbeil III, F. W., and Wesely, M. L.: Air-surface exchange of peroxyacetyl nitrate at a grassland site, J. Geophys. Res., 109, D10310, doi:10.1029/2004JD004533, 2004.

Dyer, A. J.: A review of flux-profile relationships, Bound.-Lay. Meteorol., 7, 363-372, 1974.

Faloona, I. C., Tan, D., Lesher, R. L., Hazen, N. L., Frame, C. L., Simpas, J. B., Harder, H., Martinez, M., Di Carlo, P., Ren, X. R., and Brune, W. H.: A laser-induced fluorescence instrument for detecting tropospheric $\mathrm{OH}$ and $\mathrm{HO}_{2}$ : Characteristics and calibration, J. Atmos. Chem., 47, 139-167, 2004.

Farmer, D. K. and Cohen, R. C.: Observations of HNO3, $\sum$ AN, $\sum \mathrm{PN}$ and $\mathrm{NO}_{2}$ fluxes: evidence for rapid $\mathrm{HO}_{\mathrm{x}}$ chemistry within a pine forest canopy, Atmos. Chem. Phys., 8, 3899-3917, 2008, http://www.atmos-chem-phys.net/8/3899/2008/.

Farmer, D. K., Wooldridge, P. J., and Cohen, R. C.: Application of thermal-dissociation laser induced fluorescence (TD-LIF) to measurement of $\mathrm{HNO}_{3}$, Salkyl nitrates, Speroxy nitrates, and $\mathrm{NO}_{2}$ fluxes using eddy covariance, Atmos. Chem. Phys., 6, 3471-3486, 2006, http://www.atmos-chem-phys.net/6/3471/2006/.

Foken, T. and Wichura, B.: Tools for quality assessment of surfacebased flux measurements, Agr. Forest Meteorol., 78, 83-105, 1996.

Gao, W., Wesely, M. L., and Lee, I. Y.: A numerical study of the effects of air chemistry on fluxes of $\mathrm{NO}, \mathrm{NO}_{2}$, and $\mathrm{O}_{3}$ near the surface, J. Geophys. Res., 96(D10), 18761-18769, 1991.

Garland, J. A. and Penkett, S. A.: Absorption of peroxy acetyl nitrate and ozone by natural surfaces, Atmos. Environ., 10, 1127$1131,1976$.

Gerosa, G., Derghi, F., and Cieslik, S.: Comparison of Different Algorithms for Stomatal Ozone Flux Determination from Micrometeorological Measurements, Water Air Soil Pollut., 179, 309-321, 2007.

Goldstein, A. H., Hultman, N. E., Fracheboud, J. M., Bauer, M. R., Panek, J. A., Xu, M., Qi, Y., Guenther, A. B., and Baugh, 
W.: Effects of climate variability on the carbon dioxide, water, and sensible heat fluxes above a ponderosa pine plantation in the Sierra Nevada (CA), Agr. Forest Meteorol., 101, 113-129, 2000. Goldstein, A. H., McKay, M., Kurpius, M. R., Schade, G. W., Lee, A., Holzinger, R., and Rasmussen, R. A.: Forest thinning experiment confirms ozone deposition to forest canopy is dominated by reaction with biogenic VOCs, Geophys. Res. Lett., 31, L22106, doi:10.1029/2004GL021259, 2004.

Goulding, K. W. T., Bailey, N. J., Bradbury, N. J., Hargreaves, P., Howe, M., Murphy, D. V., Poulton, P. R., and Willison, T. W.: Nitrogen deposition and its contribution to nitrogen cycling and associated soil processes, New Phytol., 139, 49-58, 1998.

Grosjean, D., Grosjean, E., and Williams, E. L.: Thermal decomposition of PAN, PPN and vinyl-PAN, Air and Waste, 44(4), 391396, 1994a.

Grosjean, D., Grosjean, E., and Williams, E. L., II: Thermal decomposition of C3-substituted peroxyacyl nitrates, Res. Chem. Intermed., 20(3-5), 447-461, 1994b.

Hill, A. C.: Vegetation: A Sink for Atmospheric Pollutants, Japca. J. Air. Waste Ma., 21(6), 341-346, 1971.

Højstrup, J.: A statistical data screening procedure, Meas. Sci. Technol., 4, 153-157, 1993.

Holzinger, R., Lee, A., Paw, K. T., and Goldstein, U. A. H.: Observations of oxidation products above a forest imply biogenic emissions of very reactive compounds, Atmos. Chem. Phys., 5, 67-75, 2005,

http://www.atmos-chem-phys.net/5/67/2005/.

Horst, T. W.: A simple formula for attenuation of eddy fluxes measured with first-order-response scalar sensors, Bound.-Lay. Meteorol., 82, 219-233, 1997.

Hudman, R. C., Jacob, D. J., Cooper, O. R., Evans, M. J., Heald, C. L., Park, R. J., Fehsenfeld, F., Flocke, F., Holloway, J., Hübler, G., Kita, K., Koike, M., Kondo, Y., Neuman, A., Nowak, J., Oltmans, S., Parrish, D., Roberts, J. M., and Ryerson, T.: Ozone production in transpacific Asian pollution plumes and implications for ozone air quality in California, J. Geophys. Res., 109, D23S10, doi:10.1029/2004JD004974, 2004.

Jensen, N. O. and Hummelshøj, P.: Derivation of canopy resistance for water vapour fluxes over a spruce forest, using a new technique for the viscous sublayer resistance, Agr. Forest Meteorol., 73, 339-352, 1995.

Jensen, N. O. and Hummelshøj, P.: Erratum to "Derivation of canopy resistance for water vapor fluxes over a spruce forest, using a new technique for the viscous sublayer resistance", Agr. Forest Meteorol., 85, p. 289, 1997.

Kaimal, J. C. and Finnigan, J. J.: Atmospheric Boundary Layer Flows: Their Structure and Measurement, Oxford University Press, Inc., New York, NY, USA, 1994.

Kames, J. and Schurath, U.: Henry's Law and Hydrolysis-Rate Constants for Peroxyacyl Nitrates (PANs) Using a Homogeneous Gas-Phase Source, J. Atmos. Chem., 21, 151-164, 1995.

Kotchenruther, R. A., Jaffe, D. A., and Jaeglé, L.: Ozone photochemistry and the role of peroxyacetyl nitrate in the springtime northeastern Pacific troposphere: Results from the Photochemical Ozone Budget of the Eastern North Pacific Atmosphere (PHOBEA) campaign, J. Geophys. Res., 106(D22), 2873128742, 2001.

Kurpius, M. R. and Goldstein, A. H.: Gas-phase chemistry dominates $\mathrm{O}_{3}$ loss to a forest, implying a source of aerosols and hy- droxyl radicals to the atmosphere, Geophys. Res. Lett., 30(7), 1371-1374, doi:10.1029/2002GL016785, 2003.

Kurpius, M. R., Panek, J. A., Nikolov, N. T., McKay, M., and Goldstein, A. H.: Partitioning of water flux in a Sierra Nevada ponderosa pine plantation, Agr. Forest Meteorol., 117, 173-192, doi:10.1016/S0168-1923(03)00062-5, 2003.

LaFranchi, B. W., Wolfe, G. M., Thornton, J. A., et al.: Observations of acyl peroxy nitrates (PAN, PPN, and MPAN) during BEARPEX 2007: Constraints on temperature dependent sources of peroxy acetyl and hydroxyl $(\mathrm{OH})$ radicals, Atmos. Chem. Phys, accepted, 2008.

Lee, X., Massman, W., and Law, B.: Handbook of Micrometeorology: A Guide for Surface Flux Measurement and Analysis, Kluwer Academic Publishers, Dordrecht, The Netherlands, 2004.

Lenschow, D. H. and Kristensen, L.: Uncorrelated noise in turbulence measurements, J. Ocean. Atmos. Technol., 2, 68-81, 1985.

Lenschow, D. H. and Raupach, M. R.: The attenuation of fluctuations in scalar concentrations through sampling tubes, J. Geophys. Res., 96, 5259-5268, 1991.

Magnani, F., Mencuccini, M., Borghetti, M., Berbigier, P., Berninger, F., Delzon, S., Grelle, A., Hari, P., Jarvis, P. G., Kolari, P., Kowalski, A. S., Lankreijer, H., Law, B. E., Lindroth, A., Loustau, D., Manca, G., Moncrieff, J. B., Rayment, M., Tedeschi, V., Valentini, R., and Grace, J.: The human footprint in the carbon cycle of temperate and boreal forests, Nature, 447, 7146, 849-851, 2007.

Massman, W.: The Attenuation of Concentration Fluctuations in Turbulent Flow Through a Tube, J. Geophys. Res., 96(D8), 15269-15273, 1991.

McFadyen, G. G. and Cape, J. N.: Physical and chemical influences on PAN concentrations at a rural site, Atmos. Environ., 33(18), 2929-2940, 1999.

McMillen, R. T.: An eddy correlation technique with extended applicability to non-simple terrain, Bound.-Lay. Meteorol., 43, 231-245, 1988.

Mihelcic, D., Holland, F., Hofzumahaus, A., Hoppe, L., Konrad, S., Müsgen, P., Pätz, H.-W., Schäfer, H. J., Schmitz, T., Volz-Thomas, A., Bächmann, K., Schlomski, S., Platt, U., Geyer, A., Alicke, B., and Moortgat, G. K.: Peroxy radicals during BERLIOZ at Pabstthum: Measurements, radical budgets and ozone production, J. Geophys. Res., 108, 8254, doi:10.1029/2001JD001014, 2003.

Misson, L., Tang, J., Xu, M., McKay, M., and Goldstein, A.: Influences of recovery from clear-cut, climate variability, and thinning on the carbon balance of a young ponderosa pine plantation, Agr. Forest Meteorol., 130, 207-222, 2005.

Monteith, J. L. and Unsworth, M. H.: Principles of Environmental Physics, 2nd ed., Edward Arnold, London, UK, , 1990.

Moore, C. J.: Frequency response correction for eddy correlation, Bound.-Lay. Meteorol., 37, 17-36, 1986.

Moxim, W. J., Levy II, H., and Kasibhatla, P. S.: Simulated global tropospheric PAN: Its transport and impact on $\mathrm{NO}_{\mathrm{x}}, \mathrm{J}$. Geophys. Res., 101(D7), 12621-12638, 1996.

Murphy, J. G., Day, D. A., Cleary, P. A., Wooldridge, P. J., and Cohen, R. C.: Observations of the diurnal and seasonal trends in nitrogen oxides in the western Sierra Nevada, Atmos. Chem. Phys., 6, 5321-5338, 2006,

http://www.atmos-chem-phys.net/6/5321/2006/. 
National Center for Atmospheric Research (NCAR): TUV Radiation Model v4.4, online: http://cprm.acd.ucar.edu/Models/TUV/, last access: 23 May 2008, 2008.

Okano, K., Tobe, K., and Furukawa, A.: Foliar uptake of peroxyacetyl nitrate (PAN) by herbaceous species varying in susceptibility to this pollutant, New Phytol., 114, 139-145, 1990.

Orlando, J. J., Tyndall, G. S., Bertman, S. B., Chen, W., and Burkholder, J. B.: Rate coefficient for the reaction of $\mathrm{OH}$ with $\mathrm{CH}_{2}=\mathrm{C}\left(\mathrm{CH}_{3}\right) \mathrm{C}(\mathrm{O}) \mathrm{OONO}_{2}$ (MPAN), Atmos. Environ., 36, 1895-1900, 2002.

Parrish, D. D., Dunlea, E. J., Atlas, E. L., Schauffler, S., Donnelly, S., Stroud, V., Goldstein, A. H., Millet, D. B., McKay, M., Jaffe, D. A., Price, H. U., Hess, P. G., Flocke, F., and Roberts, J. M.: Changes in the photochemical environment of the temperate North Pacific troposphere in response to increased Asian emissions, J. Geophys. Res., 109, D23S18, doi:10.1029/2004JD004978, 2004.

Pilegaard, K., Jensen, N. O., and Hummelshøj, P.: Seasonal and diurnal variation in the deposition velocity of ozone over a spruce forest in Denmark, Water Air Soil Pollut., 85, 2223-2228, 1995.

Pryor, S. C. and Klemm, O.: Experimentally derived estimates of nitric acid dry deposition velocity and viscous sub-layer resistance at a conifer forest, Atmos. Environ., 38(18), 2769-2777, 2004.

Ritter, J. A., Lenschow, D. H., Barrick, J. D. W., Gregory, G. L., Sachse, G. W., Hill, G. F., and Woerner, M. A.: Airborne flux measurements and budget estimates of trace species over the Amazon Basin during the GTE/ABLE-2B Expedition, J. Geophys. Res., 95(D10), 16875-16886, 1990.

Roberts, J. M.: The Atmospheric Chemistry of Organic Nitrates, Atmos. Environ., 24A(2), 243-287, 1990.

Roberts, J. M. and Bertman, S. B.: The thermal decomposition of peroxyacetic nitric anhydride (PAN) and peroxymethacrylic nitric anhydride (MPAN), Int. J. Chem. Kinet., 24(3), 297-307, 1992.

Roberts, J. M., Flocke, F., Chen, G., de Gouw, J., Holloway, J. S., Hübler, G., Neuman, J. A., Nicks Jr., D. K., Nowak, J. B., Parrish, D. D., Ryerson, T. B., Sueper, D. T., Warneke, C., and Fehsenfeld, F. C.: Measurement of peroxycarboxylic nitric anhydrides (PANs) during the ITCT 2K2 aircraft intensive experiment, J. Geophys. Res., 109, D23S21, doi:10.1029/2004JD004960, 2004.

Rummel, U., Ammann, C., Kirkman, G. A., Moura, M. A. L., Foken, T., Andreae, M. O., and Meixner, F. X.: Seasonal variation of ozone deposition to a tropical rain forest in southwest Amazonia, Atmos. Chem. Phys., 7, 5415-5435, 2007, http://www.atmos-chem-phys.net/7/5415/2007/.

Schade, G. W., Goldstein, A. H., and Lamanna, M. S.: Are monoterpene emissions influenced by humidity?, Geophys. Res. Lett., 26, 2187-2190, 1999.

Schrimpf, W., Lienaerts, K., Mueller, K. P., Rudolph, J., Neubert, R., Schuessler, W., and Levin, I.: Dry deposition of peroxyacetyl nitrate (PAN): Determination of its deposition velocity at night from measurements of the atmospheric PAN and ${ }^{222}$ Radon concentration gradient, Geophys. Res. Lett., 23(24), 3599-3602, 1996.

Seaman, N. L., Stauffer, D. R., and Lario-Gibbs, A. M.: A multiscale four-dimensional data assimilation system applied in the San Joaquin Valley during SARMAP, I, modeling design and ba- sic performance characteristics, J. Applied Meteorol., 34, 17391761, 1995.

Shepson, P. B., Bottenheim, J. W., Hastie, D. R., and Venkatram, A.: Determination of the relative ozone and PAN deposition velocities at night, Geophys. Res. Lett., 19(11), 1121-1124, 1992.

Sievering, H., Kelly, T., McConville, G., Seibold, C., and Turnipseed, A.: Nitric acid dry deposition to conifer forests: Niwot Ridge spruce-fir-pine study, Atmos. Environ., 35(22), 38513859, 2001.

Slusher, D. L., Huey, L. G., Tanner, D. J., Flocke, F. M., and Roberts, J. M.: A thermal dissociation-chemical ionization mass spectrometry (TD-CIMS) technique for the simultaneous measurement of peroxyacyl nitrates and dintrogen pentoxide, J. Geophys. Res., 109, D19315, doi:10.1029/2004JD004670, 2004.

Sparks, J. P., Roberts, J. M., and Monson, R. K.: The uptake of gaseous organic nitrogen by leaves: A significant global nitrogen transfer process, Geophys. Res. Lett., 30(23), 2189, doi:10.1029/2003GL018578, 2003.

Talukdar, R. K., Burkholder, J. B., Schmoltner, A. M., Roberts, J. M., Wilson, R. R., and Ravishankara, A. R.: Investigation of the loss processes for peroxyacetyl nitrate in the atmosphere: UV photolysis and reaction with OH, J. Geophys. Res., 100(D7), 14163-14173, 1995.

Taylor, O. C.: Importance of peroxyacetylnitrate (PAN) as a phytotoxic air pollutant, J. Air Pollut. Cont. Assoc., 19, 347-351, 1969.

Thom, A. S.: Momentum, mass and heat exchange of plant communities, in: Vegetation and Atmosphere, edited by: Monteith, J. L., 57-109, Elsevier, New York, NY, USA, 1975.

Turnipseed, A. A., Huey, L. G., Nemitz, E., Stickel, R., Higgs, J., Tanner, D. J., Slusher, D. L., Sparks, J. P., Flocke, F., and Guenther, A.: Eddy covariance fluxes of peroxyacetyl nitrates (PANs) and $\mathrm{NO}_{\mathrm{y}}$ to a coniferous forest, J. Geophys. Res., 111, D09304, doi:10.1029/2005JD006631, 2006.

Villalta, P. W. and Howard, C. J.: Direct Kinetics Study of the $\mathrm{CH}_{3} \mathrm{C}(\mathrm{O}) \mathrm{O}_{2}+\mathrm{NO}$ Reaction Using Chemical Ionization Mass Spectrometry, J. Phys. Chem., 100, 13624-13628, 1996.

Warneck, P. and Zerbach, T.: Synthesis of peroxyacetyl nitrate in air by acetone photolysis, Environ. Sci. Technol., 26, 74-79, 1992.

Wesely, M. L.: Parameterization of surface resistances to gaseous dry deposition in regional-scale numerical models, Atmos. Environ., 23(6), 1293-1304, 1989.

Wesely, M. L. and Hicks, B. B.: A review of the current status of knowledge on dry deposition, Atmos. Environ., 34, 2261-2282, 2000.

Wolfe, G. M., Thornton, J. A., McNeill, V. F., Jaffe, D. A., Reidmiller, D., Chand, D., Smith, J., Swartzendruber, P., Flocke, F., and Zheng, W.: Influence of trans-Pacific pollution transport on acyl peroxy nitrate abundances and speciation at Mount Bachelor Observatory during INTEX-B, Atmos. Chem. Phys., 7, 53095325, 2007, http://www.atmos-chem-phys.net/7/5309/2007/.

Xu, M., DeBiase, T. A., Qi, Y., Goldstein, A., and Liu, Z.: Ecosystem respiration in a young ponderosa pine plantation in the Sierra Nevada Mountains, California, Tree Physiol., 21, 309318, 2001. 